\title{
LA EXPLOTACIÓN ECONÓMICA DEL CAMPO ARAÑUELO Y LA ECONOMÍA RURAL DE LA TIERRA DE PLASENCIA A MEDIADOS DEL SIGLO XV
}

\author{
THE ECONOMIC EXPLOITATION OF THE 'CAMPO ARANUUELO' \\ AND THE RURAL ECONOMY OF THE TERRITORY OF PLASENCIA \\ BY THE MIDDLE OF THE 15th CENTURY
}

JULIÁN CLEMENTE RAMOS Universidad de Extremadura

\begin{abstract}
Resumen: El Campo Arañuelo, comarca de la tierra de Plasencia, contaba hasta finales del siglo XV con una escasa población y abundantes pastos. Vecinos de La Vera, la zona Almonte-Tajo o de otras comarcas del término se desplazan con sus ganados o establecen una segunda vecindad en ella. La concesión de Plasencia a Pedro de Estúñiga en 1442, la existencia de numerosos señoríos en el término placentino y una coyuntura de crecimiento demográfico y agrario van a originar disputas muy importantes sobre su aprovechamiento y explotación a mediados del siglo XV. Esta conflictividad nos permitirá disponer de información muy importante sobre el comercio del cereal, las cabañas ganaderas o los desplazamientos estacionales en el término de Plasencia.
\end{abstract}

Palabras Clave: Economía rural; Ganadería; Migraciones; Extremadura; Siglo XV.

\begin{abstract}
The 'Campo Arañuelo', district of the Plasencia's land, until final of the century XV bill with a scarce population and abundant grasses. Neighbors of $\mathrm{La}$ Vera, the area Almonte-Tajo or of other districts of the term they move with their livestocks or they establish a second vicinity in her. The concession of Plasencia to Pedro of Stúñiga in 1442, the existence of numerous seignorials estates in the term of Plasencia and a joint of demographic and agrarian growth will originate very important disputes on its use and exploitation by the middle of the XV century. This conflict will allow to have very important information on the trade of the cereal, the cattle cabins or the seasonal displacements in the term of Plasencia.
\end{abstract}

Keywords: Rural Economy; Cattle raising; Migrations; Extremadura; Fifteenth Century.

\section{SUMARIO}

1. Notas sobre la economía rural de la tierra de Plasencia.- 1.1. El cereal: producción y comercio.- 1.2. La ganadería autóctona.- 1.3. La doble vecindad.- 2. El Campo Arañuelo a mediados del siglo XV.- 2.1. Paisaje y explotación económica.- 2.2. Señorialización de Plasencia y derechos comunales (1442-c. 1451).- 3. Conclusiones.

La estructura particular del término placentino, con sus numerosas aldeas señorializadas y convertidas en villas (en torno a un tercio del alfoz y 
de la población), ha sido un elemento de extraordinaria importancia y una frecuente fuente de conflictos. En 1451, Diego González de Ciudad Real dictó sentencia en el pleito que mantenían las villas señoriales y la ciudad de Plasencia sobre la explotación del Campo Arañuelo ${ }^{1}$. Este enfrentamiento empezó a desarrollarse poco después de 1442, cuando el alfoz placentino pasó a depender jurisdiccionalmente de Pedro de Estúñiga. El nuevo señor va a intentar limitar los derechos de las villas señorializadas sobre los espacios comunales. La sentencia citada tiene como base un amplio interrogatorio de extraordinario interés que proyecta una intensa luz sobre el mundo rural y la sociedad campesina ${ }^{2}$. Aunque se centra en el Campo Arañuelo, las diversas informaciones afectan en grado diverso al resto de las comarcas placentinas. La doble vecindad, el comercio del cereal, los aprovechamientos comunales, la ganadería estante y otros muchos aspectos, con una escasa presencia en otras fuentes documentales, quedan suficientemente iluminados. Desde nuestro primer contacto con esta fuente pensamos abordar su estudio, imprescindible para un buen conocimiento de la comarca morala, que presenta un perfil muy definido. Conforme avanzamos en el mismo, vimos que toda la problemática y los aprovechamientos vinculados a este territorio no podían entenderse al margen de la realidad demográfica, agraria y pecuaria del resto del término, de donde procedía gran parte del ganado y la población que explotaba o habitaba la zona. Mucha de la información que aportamos tiene un interés retrospectivo, al proyectar luz sobre realidades más antiguas.

El Campo Arañuelo es una comarca escasamente poblada hasta finales del siglo XV. Contaba con extensos espacios comunales. En un momento que desconocemos, pero sin duda conforme se han ido colmatando las zonas de montaña, ha adquirido una importancia fundamental por su disponibilidad de pastos y tierras de cultivo. No es, por tanto, una zona escasamente explotada pese a su limitada población. Vecinos de otras comarcas placentinas buscan en ella una fuente de aprovisionamiento de cereal y de pastos para sus ganados. Trazar el perfil agropecuario del Campo Arañuelo nos sitúa, por tanto, indirectamente ante la realidad económica y específicamente rural de todo o gran parte del territorio placentino.

\section{NotAS SOBRE LA ECONOMÍA RURAL DE LA TIERRA DE PLASENCIA}

\subsection{El cereal: producción y comercio}

El aprovisionamiento de cereal se ha convertido a mediados del siglo $\mathrm{XV}$ en un componente fundamental de las relaciones entre Plasencia y las

${ }^{1}$ Este conflicto ha sido estudiado por Alfonso Franco SILVA y José Luis DEL PINO GARCía, El Campo de Arañuelo en el siglo XV: problemas y conflictos entre los señores de Oropesa y la ciudad de Plasencia, "Estudios sobre ordenanzas municipales (siglos XIV-XVI)", Cádiz, 1998, pp. 207-219.

${ }^{2}$ AHN (Archivo Histórico Nacional), Nobleza, Frías, leg. 1367, nº 1, ff. 147 r.-351 r. 
villas de su tierra. En algunas comarcas se ha ido perfilando un claro modelo de economía de montaña, con un acusado déficit cerealista (cf. cuadro 1) ${ }^{3}$. Es un aspecto que condiciona especialmente la doble vecindad de muchos habitantes de la Vera o el Valle del Jerte, que tienen una segunda residencia en el Campo Arañuelo.

La Vera y el Valle del Jerte presentan a mediados del siglo XV un claro déficit cerealista ${ }^{4}$. Sin duda, es una realidad generalizada aunque nuestra información se centra en las villas señoriales. Esta situación ha generado unos circuitos comerciales que se han visto parcialmente alterados después de la señorialización de Plasencia en 1442. Hasta entonces, la mayor parte del comercio del cereal se ha debido desarrollar dentro de la propia jurisdicción placentina. Es evidente que parte del abastecimiento no tenía un carácter comercial y venía facilitado por la actividad económica que vecinos del Valle del Jerte y, sobre todo, de la Vera realizaban en el Campo Arañuelo. No nos cabe ninguna duda de la enorme importancia de esta comarca en el abastecimiento cerealista de las zonas de montaña. También debemos considerar entre los mecanismos de aprovisionamiento las rentas por alquiler de bueyes.

No es fácil precisar la importancia real de las comarcas vendedoras, puesto que muy frecuentemente se alude a Plasencia, que tiene una mera función redistribuidora, o a su tierra en general. De Plasencia parte cereal hacia Tornavacas, Garganta la Olla, Aldeanueva de la Vera, Pasarón y las villas señoriales en general. En definitiva, las aldeas y villas situadas en las comarcas montañosas se abastecen en esta ciudad de escasa producción agraria.

Los centros productores son otros. Uno de ellos está constituido por las aldeas menudas. En esta comarca, la actividad de los vecinos de Tornavacas parece tener una especial importancia. Obtienen cereal por diversos medios en el río Torrillo, Serradilla o los Barbadones.

El Campo Arañuelo también es otra zona de aprovisionamiento. Vecinos de la Vera obtienen cereal en Valparaíso y Peraleda mediante compra

\footnotetext{
${ }^{3}$ Para una contextualización regional de esta problemática, con numerosas referencias a la jurisdicción placentina, cf. Julián CLEMENTE RAMOS, La economía de montaña en Extremadura (siglos XV-XVI), "Guadalupe y la Orden Jéronima. Un empresa innovadora", Mérida, 2008, pp. 19-21. El déficit cerealista es un rasgo generalizado de las zonas de montaña: Francisco Javier PÉREZ-EMBID WAMBA, Aracena y su sierra. La formación histórica de una comunidad andaluza (siglos XIII-XVIII), Huelva, 1995, p. 102; Carmelo LUIS LÓPEZ, Las comarcas meridionales de la tierra abulense medieval: precisiones a una problemática delimitación y repoblación. "Studia Historia - Historia Medieval", 20-21 (2002-3), pp. 38-40. Esta dinámica se mantiene en la época moderna: Enrique LLOPIS AGELÁN, Población y producción agraria en Guadalupe (1661-1741), "Congreso de Historia Rural. Siglos XV al XIX". Madrid, 1984, p. 369. Las zonas de montana presentan en muchos casos una gran importancia de la economía pecuaria: Henri FALQUE-VERT, Les hommes et la montagne en Dauphine au XIII ${ }^{e}$ siecle, Grenoble, 1997, p. 67. No debemos olvidar, en todo caso, que los productos agrarios y ganaderos constituyen el componente fundamental del comercio local e intercomarcal (cf. Francis BRUMONT, Campos y campesinos de Castilla la Vieja en tiempos de Felipe II, Madrid, 1984, p. 168).

${ }^{4}$ Esta situación ha generado una importancia creciente del consumo de las castañas entre los sectores más humildes (Julián CLEMENTE RAMOS, Explotación del bosque y paisaje natural en la tierra de Plasencia [1350-1550], "IX Congreso de Historia Agraria", Bilbao, 1999, pp. 448-9). Es sintomático que un siglo más tarde el mayordomo de Carlos V afirmase que "lo que hay de bueno aquí [Jarandilla de la Vera] son las castañas, no el trigo, y el que se encuentra es terriblemente caro" (Fernand BRAUDEL Civilización material y capitalismo, Barcelona, 1974, $\mathrm{p}$. 91).
} 
o renta de bueyes. Todo nos hace pensar que la importancia de esta comarca está subvalorada. El fenómeno de la doble vecindad debió jugar un papel importante.

Las villas señoriales se ven obligadas a comprar cereal fuera de la tierra de Plasencia. Es muy posible que los nuevos centros de aprovisionamiento sólo hayan adquirido importancia de forma reciente como consecuencia de las normativas restrictivas que sobre la saca de pan se aprueban a partir de 1442. Tornavacas se abastece en la tierra de Galisteo y en Coria, mientras las villas veratas lo hacen hacia el este, en la tierra de Oropesa o zonas próximas (Alarza, Calzada, Villar).

El cereal, por tanto, es objeto de una activo comercio en la tierra de Plasencia. Hasta mediados del siglo $\mathrm{XV}$, todo parece indicar que este territorio ha funcionado como una unidad económica al margen de las diversas dependencias jurisdiccionales. Esta realidad no puede entenderse sin el desarrollo de una importante dedicación vitícola en las comarcas montañosas. Se desarrolla, de este modo una clara complementariedad económica llanura/montaña, con flujos comerciales bidireccionales ${ }^{5}$.

Algunos ejemplos concretos nos permitirán captar con más detalle la complejidad del abastecimiento cerealista. Tornavacas es uno de los lugares mejor documentados (cf. mapa 2). Plasencia parece un punto de abastecimiento habitual ${ }^{6}$, hecho como hemos visto poco vinculado a la producción. También compraban cereal en la tierra de Galisteo (Galisteo, Riolobos y Holguera $^{7}$, posiblemente desde poco tiempo antes y como consecuencia de las crecientes normativas restrictivas. Algunos vecinos se desplazaban durante una parte del año hacia otros lugares para desarrollar sus actividades agrícolas y ganaderas. Se documentan en el Campo Arañuelo. Es el caso de Alfonso Sánchez, Gonzalo Pérez y Diego Sánchez que, por las presiones de Plasencia, "se ovieron de partir de la dicha labrança". A Aparecen "de gran tienpo a esta parte" en la zona de los Barbadones. Además de llevar sus cabras se dedicaban "a labrar alla por pan" . Estas migraciones estacionales debieron tener una importancia considerable en el abastecimiento de cereal. La información sobre la comarca de las aldeas menudas es más precisa. Un tal Mateo llevaba cereal a Tornavacas procedente de "su labrança que labrava en el termino de la Serradilla" ${ }^{10}$. Posiblemente tuviera el mismo origen el cereal

\footnotetext{
5 “e aun dixo este testigo que sabe que sy trahen vino de las dichas villas de señorios a los lugares de tierra de Plasençia que ge lo toman e no ge lo dexan vender, ni a los de los lugares de último tercio del siglo XV, Plasencia consume vino de aldeas veratas como Jaraíz, Aldeanueva y Cuacos (Biblioteca Pública de Cáceres, ms. 35, f. 165 r.).

${ }^{6} \mathrm{Gonzalo}$ Martin del Corral nos indica que "este testigo e otros con el fueron algunas veses a la dicha çibdad a saçar pan para su mantenimiento e torno como quier que fallavan asas personas que ge lo querian vender que no les querian dar lugar el conçejo e regidores de la çibdad que lo sacasen" (AHN, Nobleza, Frías, leg. 1367, no 1, ff. 281 v.-282 r.).

${ }^{7}$ AHN, Nobleza, Frías, leg. 1367, no 1, f. 287 r.

${ }^{8}$ AHN, Nobleza, Frías, leg. 1367, no 1 , f. 284 r.

${ }^{9} \mathrm{AHN}$, Nobleza, Frías, leg. $1369, \mathrm{n}^{\mathrm{o}} 2$, ff. 13 v. -14 r.

${ }^{10} \mathrm{AHN}$, Nobleza, Frías, leg. 1367, no 1 , f. 346 r.
} 
transportado desde la zona próxima del río Torrillo por Alfonso Sánchez y su yerno $^{11}$. A las labores realizadas en otras comarcas se unían, como fuentes de abastecimiento, los salarios de siega (mesiego) y al alquiler de bueyes (renta de bueyes). Entre las reclamaciones que Tornavacas presenta en 1451 ante Diego González de Ciudad Real se alude a los que "van a ganar a mesego a la dicha çibdad e a qualesquier lugares de su tierra" y a las "rentas de nuestros bueyes que les arrendamos [a Plasencia y sus aldeas] con que labren"12. A juzgar por estas reclamaciones, algunos vecinos de Tornavacas realizaban trabajos de siega o cedían bueyes a renta en comarcas de la jurisdicción placentina presumiblemente excedentarias en cereal. No nos falta información concreta de estos mecanismos de abastecimiento. Alfonso, hijo de Gonzalo Sánchez de Tornavacas, obtiene cereal de mesiego en Serradilla ${ }^{13}$. Es muy posible que estas modalidades derivasen en dedicaciones mixtas. Fernán Sánchez, Alfonso Sánchez y Pedro Fernández obtienen cereal en la zona de Barbadones que parece provenir tanto de renta de bueyes como de sus propias labranzas ${ }^{14}$.

La imagen que ofrece Tornavacas se ajustaría bastante a la realidad de mediados del siglo XV. A lo largo del año se producen toda una serie de desplazamientos estacionales que tienen como finalidad la obtención de cereal. Sin ellos no puede entenderse la economía y la sociedad de esta villa o del resto de las aldeas o villas serranas de la jurisdicción placentina.

A mediados del siglo XV, el comercio y el abastecimiento del cereal es un elemento fundamental en la jurisdicción placentina. Se perfilan una serie de líneas precisas. Plasencia tiene una gran importancia en la demanda y comercio de este producto. Sólo dos zonas parecen claramente excedentarias: el Campo Arañuelo y las aldeas menudas. Las comarcas de montaña son deficitarias. En conjunto, todo nos hace pensar en una producción autosuficiente de la tierra de Plasencia. No nos consta la compra de este producto fuera de la misma salvo por parte de las villas señoriales afectadas por las restricciones de la saca del pan.

\footnotetext{
11 “Alfonso Sanches fijo de Mingo Gil e un su yerno, vesinos de Torrnavacas, trayendo tres o quatro bestias cargadas de pan poco antes o despues desta Pascua de Navidad que paso deste dicho año de rio Tortillo o çerca dende tierra de Plasençia... e que sabe que ge lo tornaron por carta e mandado de don Alvaro Destuñiga e que lo sabe por que lo vido" (AHN, Nobleza, Frias, leg. $1367, \mathrm{n}^{\mathrm{O}} 1$, ff. 286 v.-287 r.).

${ }^{12}$ AHN, Nobleza, Frías, leg. 1369, no 2, f. 12 v.

${ }^{13} \mathrm{AHN}$, Nobleza, Frías, leg. 1367, no 1 , f. 282 r.; quizás sea el mismo citado en f. $271 \mathrm{v}$.

14“"e el pan que ganavan de rentas de sus bueys que ge lo contrallavan e no les querian dar lugar en la çibdad que lo llevasen a sus casas fasta tanto que ya juravan antel corregidor mesmo que era de sus rentas e labranças" (AHN, Nobleza, Frías, leg. 1367, no 1, f. 287 r.).
} 


\section{CUADRO No 1 \\ Comercio y abastecimiento cerealista en la tierra de Plasencia (c.1450)}

Fuente: AHN, Nobleza, Frías, leg. 1367, $\mathrm{n}^{\circ}$ 1)

\begin{tabular}{|c|c|c|c|}
\hline Origen & Destino & Concepto (persona; otros) & Año \\
\hline Tierra Plasencia & $\begin{array}{l}\text { villas seño- } \\
\text { riales }\end{array}$ & compra (Antón Sánchez, del Losar) & - \\
\hline tierra de Plasencia & señoríos & $\begin{array}{l}\text { compra (Fernando Sánchez Truche- } \\
\text { ro, vo Collado) }\end{array}$ & $\begin{array}{l}\text { desde hace } 45 \\
\text { años }\end{array}$ \\
\hline Valparaíso & Valverde & compra (judío de V.) & - \\
\hline ¿Tierra de Plasencia? & Valverde & - (De la Plaza, judío de V.) & - \\
\hline ¿Campo Arañuelo? & Valverde & $\begin{array}{l}\text { - (hijo de Juan García y Pedro Gar- } \\
\text { cía) }\end{array}$ & - \\
\hline Alarza & Valverde & $\begin{array}{l}\text { mesiego (vecino de Valverde) } \\
\text {-inicialmente interceptado-) }\end{array}$ & $1445-46$ \\
\hline Valparaíso & $\begin{array}{l}\text { Villanueva } \\
\text { y Valverde }\end{array}$ & $\begin{array}{l}\text { - (Juan Blázquez, vo Villanueva y } \\
\text { vecs. V.) }\end{array}$ & - \\
\hline $\begin{array}{l}\text { Tierra y ciudad Pla- } \\
\text { sencia }\end{array}$ & Pasarón & $\begin{array}{l}\text { - (Pascual Gómez, vec. de P. } \\
\text { "lo saco asas veses-) }\end{array}$ & tiempo atrás \\
\hline Plasencia & Pasarón & compra (intento infruct. por veda) & ¿1451? \\
\hline Aldea de Plasencia & Pasarón & - (Alfonso Sánchez de Salamanca) & 1450 \\
\hline ¿Tierra de Plasencia? & Pasarón & - (dos hombres de P.; interceptados) & - \\
\hline aldea Plasencia & Pasarón & renta de bueyes (un vecino de P.) & - \\
\hline La Jara & Jarandilla & $\begin{array}{l}\text { - (Alfonso Sánchez Ventealo -una } \\
\text { carga-) }\end{array}$ & - \\
\hline Tierra Plasencia & Jarandilla & $\begin{array}{l}\text { renta de bueyes (Alfonso Sánchez } \\
\text { Ventealo) }\end{array}$ & - \\
\hline Peraleda & Jarandilla & $\begin{array}{l}\text { renta un buey (Ventealo Ganado } \\
\text {-carga trigo-; ¿interceptado?) }\end{array}$ & 1450 \\
\hline indeterminado & ¿Jarandilla? & - (Pedro Cano de Jarandilla) & \\
\hline Peraleda & Jarandilla & $\begin{array}{l}\text { compra (¿Bastaedillo?, judío, } v^{o} \\
\text { Jarandilla) }\end{array}$ & 1447 \\
\hline La Calzada & Jarandilla & $\begin{array}{l}\text { compra (lugar de aprovisionamien- } \\
\text { to) }\end{array}$ & - \\
\hline Villar (Talavera?) & Jarandilla & $\begin{array}{l}\text { mesiego (Diego Sánchez Acedo, vo } \\
\text { Jarandilla) }\end{array}$ & - \\
\hline Losar & Jarandilla & - (hombres y mujeres de J.) & $1442-\ldots$ \\
\hline
\end{tabular}




\begin{tabular}{|c|c|c|c|}
\hline $\begin{array}{l}\text { Lugares término Pla- } \\
\text { sencia }\end{array}$ & Jarandilla & $\begin{array}{l}\text { - (pan tomado a Gonzalo Fernández } \\
\text { de J., alcabalero }\end{array}$ & - \\
\hline paso por Valparaíso & $\begin{array}{l}\text { ¿villas seño- } \\
\text { riales? }\end{array}$ & - (judío Manuel) & - \\
\hline Plasencia & Aldeanueva & compra (varias cargas) & 1451 \\
\hline Arroyomolinos V. & $\begin{array}{l}\text { Garganta la } \\
\text { Olla }\end{array}$ & compra (interceptada) & 1447 \\
\hline Plasencia & $\begin{array}{l}\text { Garganta la } \\
\text { Olla }\end{array}$ & $\begin{array}{l}\text { se imposibilita la venta por normati- } \\
\text { va saca }\end{array}$ & c. 1449 \\
\hline Coria & $\begin{array}{l}\text { Garganta la } \\
\text { Olla }\end{array}$ & compra (Fernando García, vº G.O.) & - \\
\hline tierra Plasencia & $\begin{array}{l}\text { Garganta la } \\
\text { Olla }\end{array}$ & - (Pedro Fernández, vº G.O.) & - \\
\hline $\begin{array}{l}\text { Serradilla; quizás } \\
\text { también Plasencia }\end{array}$ & $\begin{array}{l}\text { Garganta la } \\
\text { Olla }\end{array}$ & ¿compra? (4 vecs.G.O.-dos recuas-) & 1451-abril \\
\hline tierra Plasencia & $\begin{array}{l}\text { Jaraicejo y } \\
\text { señoríos }\end{array}$ & - (habitual incluso 1451) & - \\
\hline term. Plasencia & Tornavacas & $\begin{array}{l}\text { mesiego (Alfonso Goniado, } \mathrm{v}^{\mathbf{o}} \text { Tor- } \\
\text { navacas) }\end{array}$ & - \\
\hline Plasencia & Tornavacas & $\begin{array}{l}\text { compra (punto habitual de abasteci- } \\
\text { miento) }\end{array}$ & - \\
\hline Cabezuela & Tornavacas & $\begin{array}{l}\text { - (dos asnos cargados de pan; inter- } \\
\text { ceptados) }\end{array}$ & - \\
\hline Serradilla & Tornavacas & $\begin{array}{l}\text { mesiego (Alfonso, hj. Gonzalo Sán- } \\
\text { chez de T.; inicialmente intercepta- } \\
\text { do, luego permitido) }\end{array}$ & - \\
\hline zona río Torrillo & Tornavacas & $\begin{array}{l}\text { ¿cosecha propia? (Alfonso Sánchez } \\
\text { y su yerno;vecs. de T.- inic. inter- } \\
\text { ceptado, luego permitido-) }\end{array}$ & navidad $1450-51$ \\
\hline zona Barbadones & Tornavacas & $\begin{array}{l}\text { rentas y labranzas (Fernán Sánchez, } \\
\text { Alfonso Sánchez y Pedro Fernán- } \\
\text { dez, vecs. de T.) }\end{array}$ & - \\
\hline Serradilla & Tornavacas & labranza (Mateos, v ${ }^{\mathrm{o}}$ T.) & - \\
\hline $\begin{array}{l}\text { Riolobos, Holguera, y } \\
\text { Galisteo }\end{array}$ & Tornavacas & $\begin{array}{l}\text { compra (Juan Sánchez del Espinar, } \\
\mathrm{v}^{\mathrm{o}} \mathrm{T} \text {., y otros; parece algo habitual }\end{array}$ & - \\
\hline Riolobos & Tornavacas & $\begin{array}{l}\text { compra (Gonzalo Martín del Co- } \\
\text { rral, } v^{\mathbf{o}} \text { T.-diez cargas-) }\end{array}$ & - \\
\hline
\end{tabular}




\subsection{La ganadería autóctona}

La información de que disponemos, pese a su carácter parcial, nos permite precisar en términos cuantitativos las líneas generales de la ganadería autóctona. Podemos hacernos una idea bastante aproximada de la cabaña ganadera de algunas comunidades de la Vera y el Valle del Jerte. Conservamos una relación de las prendas realizadas a vecinos de Jarandilla de la Vera en 1446 por introducir en el Campo Arañuelo, contraviniendo las normativas, "vacas e novillos e ovejas e carneros e cabras e cabrones e puercos e puercas" $"$. El ganado prendado era el siguiente:

\begin{tabular}{|l|c|}
\hline \multicolumn{1}{|c|}{ Propietario } & Cantidad \\
\hline Juan Fernández, escribano & 300 vacas \\
\hline Ventealo Ganado y su compañero Antón Sánchez & 600 ovejas \\
\hline Juan González de San Benito & 50 vacas \\
\hline Diego García de San Benito & 50 vacas \\
\hline Juan de las Zahurdas & 60 vacas \\
\hline 25 vecinos más un $\mathrm{n}^{\circ}$ indeterminado & aprox. 1.500 cerdos \\
\hline
\end{tabular}

En 1457, el recaudador Martín Ruiz de Navalperal se llevó de Jarandilla por ciertas rentas correspondientes a 1449 y 1450 "fasta quatroçientas vacas e seysçientas cabras" ${ }^{16}$. Ese mismo año, el corregidor de Plasencia, bachiller Pedro García de la Torre, ordena la ejecución por impago de rentas de bienes de varios vecinos de Jarandilla por valor de 58 mil maravedís. La ejecución se realiza sobre "dosientas colmenas e çient vacas e dosientos puercos" $" 17$.

Disponemos de dos listas de cerdos de 1442 y 1447 para esta villa, que sigue la antigua normativa en la inscripción de estos animales para el aprovechamiento del Campo Arañuelo ${ }^{18}$. Los datos globales no difieren en gran medida de los de 1446, por lo que podemos pensar que la cabaña porcina de esta localidad se mantiene dentro de unos límites precisos a mediados del siglo XV. Contabilizando puercos y cochinos, se alcanzan 1.963 cabezas en 1442 y 1.749 en 1447. En 1442 inscriben su ganado treinta y nueve propieta-

\footnotetext{
${ }^{15} \mathrm{AHN}$, Nobleza, Frías, leg. 1369, $\mathrm{n}^{\mathrm{0}} 5$.

${ }^{16}$ AHN, Nobleza, Frías, leg. 1366, no 14.

${ }^{17}$ AHN, Nobleza, Frías, leg. 1366, no 9.

${ }^{18}$ Para los datos que siguen, cf. Julián ClEMENTE RAMOS, La ganadería porcina de Jarandilla de la Vera a mediados del siglo XV, "Os reinos ibéricos na Idade Média. Livro de Homenagem ao Professor Doutor Humberto Carlos Baquero Moreno", 3 vols., Oporto, 2003, vol. II, p. 749.
} 
rios y en 1447, sólo veintitrés. De todos estos datos podemos sacar algunas conclusiones. Antes de la señorialización de Plasencia en 1442, varias decenas de propietarios de Jarandilla desplazaban unos dos mil cerdos al Campo Arañuelo. Es posible que a partir de esta fecha, los crecientes problemas vinculados al aprovechamiento de esta comarca hayan disuadido a los propietarios más modestos (en 1447, casi desaparecen los que cuentan con menos de veinticinco cabezas). De este modo, disminuye el ganado desplazado y, en mayor proporción, el número de propietarios implicados. Podríamos considerar cifras normales, a juzgar por la información disponible para 1446 y 1447 , en torno a veinte-veinticinco propietarios y mil quinientos a mil setecientos cincuenta cerdos.

Los datos disponibles sobre otras localidades veratas son más escuetos, pero nos permite confirmar la existencia de una cabaña heterogénea. En 1447 ó 1450, se realiza una prenda de cuatrocientas cabras en Valverde de la Vera ${ }^{19}$. En Viandar también tiene una enorme importancia el ganado caprino, del que se realizan diversas prendas entre 1446 y 1449. Gonzalo García de Valverde señala que hacia 1449 "prendaron a seys omes de Biandar, aldea de Valverde, e llevaron çierto ganado cabruno fasta mill cabeças e mas e fasta quarenta puercos" ${ }^{20}$. Hacia 1448, Valverde realizó prendas sobre cabezas de ganado vacuno del $\operatorname{Losar}^{21}$.

También disponemos de valiosa información sobre Tornavacas (Valle del Jerte), perteneciente, al igual que Jarandilla, al conde de Oropesa. En 1453 se realiza una pesquisa sobre los agravios que recibe de Plasencia desde la donación de esta ciudad a Pedro de Estúñiga ${ }^{22}$. Las ovejas de esta villa se desplazaban al Campo Arañuelo, donde fueron prendadas "çiento e veynte e seys cabeças de ovejas e de cabras". Fernán Sánchez aparece con sus ovejas cerca del Escorial, junto a la dehesa boyal de Jarandilla, que luego se cederá al Losar. También las vacas realizaban el mismo desplazamiento al Campo Arañuelo. Quizás debido a las nuevas normativas van a dehesas privadas. En la de Herguijuela, perteneciente al mayorazgo de Belvís, Plasencia prendó "çiento e veynte e çinco cabeças de vacas de los vesinos desta dicha villa". Los vecinos de Tornavacas tenían costumbre "de gran tienpo a esta parte de se yr a envernar con sus cabras cada año" a los Barbadones ${ }^{23}$. Vacas, ovejas y cabras parecen tener importancia en la cabaña ganadera de Tornavacas, donde los cerdos no parecen disfrutar de un peso especial ${ }^{24}$.

Jerte, sin embargo, aldea colindante a Tornavacas, aprovechaba desde hacia once años (c. 1440), por concesión de la reina María, un espacio del

\footnotetext{
${ }^{19}$ AHN, Nobleza, Frías, leg. 1367, $\mathrm{n}^{\text {o }} 1$, f. 184 v.

${ }^{20} \mathrm{AHN}$, Nobleza, Frías, leg. 1367, no 1 , f. 251 v.

${ }^{21}$ AHN, Nobleza, Frías, leg. 1367, no 1, f. 239 r.

${ }^{22}$ AHN, Nobleza, Frías, leg. 1369, $\mathrm{n}^{\mathrm{o}} 7$.

${ }^{23} \mathrm{AHN}$, Nobleza, Frías, leg. $1369, \mathrm{n}^{\mathrm{o}} 2$, ff. 13 v.-14 r.

${ }^{24}$ En las prendas registradas en el interrogatorio de 1451 no se alude a estos animales (AHN, Nobleza, Frías, leg. $1367, \mathrm{n}^{\mathrm{O}} 1$, ff. 284,286 y 289 v.).
} 
monte del Castañar "con fasta quinientos o seysçientos puercos" 25 . Esta aldea cuenta con el $23,84 \%$ de la población (año 1494$)^{26}$ y aproximadamente el $31 \%$ de la cabaña porcina (mediados del XV) de Jarandilla.

En el Campo Arañuelo disponemos de información para algunas villas. En Almaraz se prendaron ciento cincuenta ovejas y quince bueyes en 1448 y en esta villa y en Belvís, trescientas ovejas y catorce bueyes en $1449^{27}$. Los datos relativos a Serrejón son más precisos. Disponemos de un listado de prendas realizadas en $1444^{28}$. El ganado prendado es el siguiente:

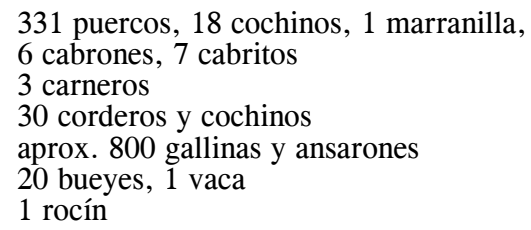

La ganadería de Serrejón se caracteriza por el predominio de los cerdos, frente a un peso muy escaso de cabras, ovejas y vacas ${ }^{29}$.

Los ejemplos de Jarandilla y Serrejón, con datos incompletos pero representativos y que quizás representen dos modelos distintos, permiten un esbozo cuantitativo del peso y valor económico de las diversas especies pecuarias $^{30}$. En Serrejón, el ganado porcino es el que alcanza un mayor valor; junto al mismo, solo parece tener importancia el ganado bovino, en particular los animales de labranza (44,09\% del valor del ganado porcino), vinculados a la actividad agraria. Las demás especies tienen un valor económico marginal.

Si consideramos el ganado prendado a vecinos de Jarandilla en 1446 (debemos considerar que no están representados los bueyes), el peso de las diversas especies sería el siguiente:

\begin{tabular}{|l|c|c|}
\hline Especie & Cabezas (\%) & Valor econ. (\%) \\
\hline Bovina (vacas) & 17,97 & 57 \\
\hline
\end{tabular}

\footnotetext{
${ }^{25}$ AHN, Nobleza, Frías, leg. 1369 , no 2 , f. 3 r.

${ }^{26}$ E.C. DE SANTOS, La historia medieval de Plasencia, pp. 103-4.

${ }^{27}$ AHN, Nobleza, Frías, leg. 1367, no 1 , ff. 220 v. y 309 r.

${ }^{28} \mathrm{AHN}$, Nobleza, Frías, leg. 1369, $\mathrm{n}^{\circ}$ 63-1.

${ }^{29}$ En 1408, el finado García González de Herrera, señor de Serrejón , tenía en esta localidad el siguiente ganado: dos novillos, una vaca parida, cien ovejas, nueve cabras y cabrones, setenta puercos y puercas, tres añales y cincuenta cochinos (Alfonso FRANCO SILVA, La hacienda de un noble castellano a comienzos del siglo XV. El mariscal García González de Herrera, "La fortuna y el poder. Estudios sobre las bases económicas de la aristocracia castellana [s. XIV-XV]" Cádiz, 1996, p. 387). Se constata, lo que no es frecuente en las cabañas señoriales, el peso del ganado porcino.

${ }^{30}$ Utilizaremos los precios medios que hemos documentado en Medellín a finales del siglo XV: vaca, $1.375 \mathrm{mrs}$.; oveja, $100 \mathrm{mrs}$.; puerco, 278,09 mrs. (J. CLEMENTE, Notas sobre la ganadería estante, p. 154, cuadro 1).
} 


\begin{tabular}{|l|c|c|}
\hline Ovina & 23,44 & 5,41 \\
\hline Porcina & 58,59 & 37,59 \\
\hline
\end{tabular}

Las cabañas ganaderas del Valle del Jerte, La Vera o el Campo Arañuelo presentan un perfil cualitativo nítido. La ganadería autóctona (estante y/o riberiega) es un sector de gran relevancia. La acusada importancia del ganado porcino se presenta como una evidencia. Debemos considerar, en primer lugar, su número y su peso en el conjunto de la cabaña. En segundo, la elevada cantidad de propietarios implicados. Los privilegios de que gozan estos propietarios constituyen un indicador del peso político de los grupos pecheros de nivel medio o acomodado. En conjunto, estamos ante cabañas diversificadas en la que también tienen importancia las vacas, ovejas y cabras. La propiedad del ganado vacuno, a juzgar por el ejemplo de Jarandilla, parece presentarse de modo más concentrado. En esta villa aparecen hatos de más de cincuenta vacas (equivalente a unos doscientos cincuenta cerdos), pudiéndose superar de forma holgada esta cantidad. Es posible que la propiedad ovina se ajuste a un patrón similar a juzgar por la cabaña de Ventealo Ganado y su compañero. Un rasgo llamativo es el peso que, al menos en la comarca verata, tienen las cabras. Quizás sea una peculiaridad de las economías de montaña ${ }^{31}$.

\subsection{La doble vecindad}

En el siglo XV, y quizás ya antes, se desarrollan amplios desplazamientos estacionales dentro de la tierra de Plasencia vinculados a los aprovechamientos agrarios y ganaderos. Este fenómeno, en sus diversas versiones, afectaba a bastantes pobladores. Las listas de cerdos de Jarandilla de 1442 y 1447 son ilustrativas. En torno a una treintena de vecinos llevaban puercos y cochinos al Campo Arañuelo.

Dentro de estos desplazamientos podemos distinguir dos modalidades que no son asimilables: el desplazamiento estacional con ganado o para realizar determinadas labores agrarias (siega, alquiler de bueyes) y la disponibilidad de auténticas explotaciones en lugares distintos al de la residencia oficial. Esta segundo tipo da origen a una doble vecindad, mediante la cual un vecino de una villa o aldea, generalmente serrana, desarrolla una importante, quizás a veces casi exclusiva, actividad económica en otra comarca. Esta doble vecindad tenemos que vincularla al desarrollo de una montaña bastante poblada, al menos en un sentido relativo, y con evidentes desequilibrios económicos ${ }^{32}$. El Campo Arañuelo aparece como destino

\footnotetext{
${ }^{31} \mathrm{M}^{\mathrm{a}}$ A. CARmona, La ganadería en el reino de Sevilla, p. 326. En Medellín, el ganado caprino tiene una importancia limitada (Cf. J. CLEMENTE, Notas sobre la ganadería estante, $\mathrm{p}$. 157).

${ }^{32}$ Elisa Carolina De SANTOS CANALEJO, El siglo XV en Plasencia y su tierra. Proyección de un pasado y reflejo de una época, Cáceres, 1981, p. 105 (moneda forera de 1400). Algunas comarcas serranas placentinas desarrollan un temprano poblamiento: Julián CCLEMENTE RAMOS y Juan Luis DE LA MONTAÑA CONCHIÑA, Repoblación y ocupación del espacio en Extremadura
} 
preferente y casi exclusivo. La doble vecindad de vecinos de aldeas placentinas no planteaba ningún problema. La situación cambiaba radicalmente si la persona implicada residía en una villa o aldea señorial. En este caso, al mantener su vecindad original, Plasencia perdía derechos y se veía perjudicada. Con las nuevas normativas se intenta que no se produzca ninguna distorsión entre vecindad oficial y residencia.

La información explícita más antigua sobre la doble vecindad aparece en la pesquisa realizada por Miguel Sánchez de Sepúlveda, corregidor de Plasencia, en $1431^{33}$. Todo nos hace indicar que estamos ante un fenómeno consolidado. Los vasallos señoriales que residían durante la mayor parte del año en La Parrilla, cuatro, y La Corcha eran mayoritariamente de Valverde ${ }^{34}$; Juan García y otros vecinos de Jarandilla habitaban en Torviscoso. El fenómeno era más amplio. Pobladores con doble residencia disponían de explotaciones en Torviscoso, La Corcha, Valparaíso, La Mata, Peraleda y Arroyo Casar $^{35}$. Es posible que algunas de estas pequeñas aldeas arañuelas se hayan desarrollado a partir de la actividad de vecinos de villas y aldeas veratas.

Para mediados del siglo XV, el fenómeno quizás haya cobrado una mayor intensidad debido al presumible crecimiento de la población, pero sus líneas generales se han mantenido intactas. Su importancia es mayor de lo que nos muestran las fuentes, que privilegian al sector señorializado. La doble vecindad afecta a las diversas comarcas de la tierra de Plasencia, incluyendo a la propia ciudad y sus aldeas. Aunque la información sobre el particular no es amplia algunos datos disponibles lo confirman. Vecinos de Plasencia o Losar residen en Valparaíso, Torviscoso o San Benito. Es llamativo que, en el interrogatorio de 1451, frente a catorce testigos de las villas veratas haya dieciocho del Losar, siete de Cuacos y cuatro de Aldeanueva o Collado. Aunque el pleito que nos suministra información se centre por razones obvias de carácter fiscal en las villas señorializadas, las aldeas veratas debieron suministrar igualmente muchas dobles vecindades.

Una información importante aunque aislada nos permite estimar el peso demográfico de la doble vecindad. En octubre de 1446, Luis García,

(1142-c. 1350), "Actas de las I Jornadas de Historia Medieval de Eztremadura”, Cáceres-Mérida, 2000 , pp. 31-2; Juan Luis DE LA MONTAÑA CONCHIÑA, La Extremadura cristiana (1142-1350). Poblamiento, poder y sociedad, Cáceres, 2003, pp. 62-63.

${ }^{33}$ Domingo SÁNCHEZ LoRO, Historia placentinas inéditas, Cạceres, 3 vols., 1982-5, vol. III, pp. 391-410, en concreto pp. 397, 402 y 406-7. Es llamativo, sin embargo, que en la lectura de la sentencia del pleito mantenido por Plasencia contra Esteban Fernández de Bote sobre los términos de Belvis (a. 1376), leída supuestamente en este lugar, aparezcan vecinos de Jarandilla, Jaraíz, Cuacos, Losar, Aldeanueva y Pasarón (D. SÁNCHEZ LoRO, Historia placentinas inéditas, II, pp. 298-9).

34 “saben que cuatro vecinos, poco mas o menos, que moran en las casas de La Parrilla y los que moraban y moran en La Corcha, que oyeron desir a Juan Sanches Vasallos, que mora en Valparaíso, que todos estos que pechan en el lugar de Valverde" (D. SÁNCHEZ LORO, Historia placentinas inéditas, III, p. 397).

35 "que oyeran decir que ciertos hombres que moran en Torviscoso, y en la Corcha, y en Valparaiso, y en la Mata, y. en la Peraleda, y en el Arroyo Casar, que es jurisdicción y termino de la dicha ciudad, y que viven alli la mayor parte del año, que pechan en los dichos lugares de los señoríos" (D. SÂNCHEZ LORO, Historia placentinas inéditas, III, p. 406). 
escribano de Jarandilla, da fe "de todos los dichos vesinos" que "tyenen labranças e crianças en el canpo e montes de Arañuelo pechan e contribuyen en todos los pechos e derramas que en esta dicha villa se han acaesçido a derramar e se agora derraman e reparten" ${ }^{36}$. Se enumeran veintiún vecinos. Si estimamos una población para esta villa de 350 vecinos $(70 \%$ de la documentada en 1494), estamos ante el $6 \%$ de la población. Si comparamos este contingente con la población de la campana de La Mata, que agrupa en 1494 a la mayor parte de las aldeas que acogen a estos simples moradores, y utilizamos el mismo procedimiento, estos vecinos de Jarandilla alcanzan el $7,5 \%$. Para el conjunto de las aldeas placentinas supondrían el 3,12\%. Este dato debemos valorarlo considerando que esta villa alberga el $7 \%$ de la población de la tierra de Plasencia, excluida la ciudad, en $1494^{37}$. Con seguridad estamos ante porcentajes mínimos, puesto que posiblemente hemos sobrevalorado la población que hacia mediados del siglo XV albergaban tanto Jarandilla como, sobre todo, la campana de La Mata. Si consideramos que estamos simplemente ante la población aportada por una villa señorial, podemos valorar la importancia de la doble vecindad. Una población muy numerosa en relación con la oficialmente avecindada está asentada en el Campo Arañuelo y muy posiblemente representa una parte mayoritaria en algunas aldeas (La Corcha, Torviscoso, San Benito, etc.).

En definitiva, a mediados del siglo XV, especialmente de la Vera pero también de las demás comarcas de la tierra de Plasencia, muchos vecinos de villas señoriales y aldeas placentinas establecen una segunda residencia en el Campo Arañuelo donde tienen la base de su explotación, agraria y pecuaria. Este contingente, no cuantificado como población de la comarca, suponía una parte muy importante de la misma.

\section{El CAMPo ARAÑUelo a MEdiados DEL SIGLO XV}

\subsection{Paisaje y explotación económica}

El Campo Arañuelo placentino tiene una extensión de algo menos de $1.100 \mathrm{~km}^{2}$. Los señoríos alcanzan 228,62 $\mathrm{km}^{2}$ (Serrejón, Almaraz, Belvís con Valdehúncar), algo más de una quinta parte. Estos señoríos se extienden en la parte sur, junto a los suaves relieves que marcan la divisoria entre el Tiétar y el Tajo. Se trata de los núcleos de más temprana aparición. Posteriormente, a lo largo del siglo XIV y en algún caso incluso del XV irán surgiendo diversas aldeas más al norte, disminuyendo su número conforme nos acercamos al Tiétar ${ }^{38}$. A principios del siglo XV, la población que alberga la

\footnotetext{
${ }^{36}$ AHN, Nobleza, Frías, leg. $1369, n^{\circ} 4$, ff. 4 v. -5 r.

${ }^{37}$ E. C. DE SANTOS, La historia medieval de Plasencia, pp. 100-101.

${ }^{38}$ Angel BeRnAl EsTÉVEZ, Repoblación medieval del Campo del Arañuelo, "II Coloquios histórico-culturales del Campo Arañuelo", Navalmoral de la Mata, 1996, p. 44 .
} 
comarca es muy escasa, pudiendo hablarse de casi despoblación ${ }^{39}$. En 1395 , el sexmo del Campo Arañuelo, que incluía también otras zonas, contaba sólo con 227 pecheros frente a los 741 de la Vera y los 578 del Valle (del Jerte) y la Trasierra ${ }^{40}$. Los datos del pago de la moneda forera de 1400 son más precisos. Las aldeas del Campo Arañuelo totalizaban unos 130 pecheros $^{41}$, de donde resulta una densidad aproximada de 0,7 habs. $/ \mathrm{km}^{2}$. Tienen una población superior a la indicada algunas aldeas placentinas como Cabezuela (Valle del Jerte), Jaraíz o Losar (La Vera). Aunque el carácter incompleto de los datos impide una comparación comarcal precisa, no hay duda alguna de que el Campo Arañuelo se presenta a principios del siglo XV con una escasísima población ${ }^{42}$.

Esta circunstancia ha permitido una situación que va a condicionar extraordinariamente su aprovechamiento. El territorio no señorializado, debido a la escasa apropiación desarrollada, cuenta con extensos baldíos y comunales $^{43}$. De este modo, ofrece condiciones ideales para el aprovechamiento agropecuario. Otra consecuencia de esta situación es la importancia maderera del Campo Arañuelo. El Tiétar aparece jalonado por pinares, que serán objeto de una intensa explotación ${ }^{44}$.

Hasta mediados del siglo XV hay muy pocas referencias a dehesas en la zona directamente dependiente de Plasencia. En 1441 aparece "una torre, e casas, e cortijo, que estava en el dicho logar de la Mata" perteneciente al mayorazgo de Belvís ${ }^{45}$. Posiblemente estemos ante un espacio adehesado. Se trata, sin duda, de algo excepcional ${ }^{46}$. El predominio de los baldíos $y$

${ }^{39}$ La comarca del Campo Arañuelo, que se extiende por las provincias de Cáceres, Ávila y Toledo, constituye en su conjunto un espacio escasamente poblado hasta finales del siglo XIII. José Ignacio MORENO NúNẼZ, La creación de nuevas pueblas por Alfonso X: la repoblación tardía del Campo de Arañuelo, "En la España Medieval", 15 (1992), p. 112, habla antes del inicio de su repoblación por Alfonso X de "una comarca hasta entonces prácticamente abandonada" (debemos precisar que sólo analiza las zonas abulense y toledana). C. LUIS, Las comarcas meridionales de la tierra abulense, p. 33, sitúa entre el último tercio del XIII y el último del XIV el desarrollo de una densa ocupación de la parte abulense, de distinta orografía y características físicas.

${ }^{40}$ E.C. DE SAnTos, La historia medieval de Plasencia, p. 100; sobre la extensión del sexmo, que incluía la comarca de las aldeas menudas y la zona entre el Ȧlmonte y el Tajo, p. 110.

${ }^{41}$ E.C. DE SANTOS, El siglo XV en Plasencia y su tierra, p. 105 (Collado, Casatejada y Saucedilla contaban con 77 pecheros -hemos restado un tercio de esta cantidad imputándolo a Collado, población situada en la Vera, de donde resulta la cifra indicada-).

${ }^{42}$ Serrejón contaba a principios del siglo XV con veinte vecinos; a finales de este siglo, junto a sus anejos, alcanzaba los doscientos (A. FRANCO, La hacienda de un noble castellano a comienzos del siglo XV, p. 387; E. C. DE SANTOS, La historia medieval de Plasencia, pp. 1001).

${ }^{43}$ Se entiende de este modo la afirmación de E. C. DE SANTOS, La historia medieval de Plasencia, p. 110, de que "A principios del siglo XंVI, en la documentación se habla de los sexmos de la Vera, Valle y Trasierra, y se considera el Campo del Arañuelo más que un sexmo, un término de tierras baldías y concejiles".

${ }^{44}$ J. Clemente, Explotación del bosque y paisaje natural, p. 454.

${ }^{45}$ AHN, Nobleza, Frías, leg. 1249, no 40-2, f. 16 v.

${ }^{46}$ No disponemos de una cartografía precisa de las dehesas de la tierra de Plasencia, que revelaría sin duda grandes diferencias comarcales. Es llamativo que la catedral de Plasencia apenas tuviese propiedades en el Campo Arañuelo. Sus dehesas se sitúan especialmente alrededor de Plasencia y en la zona de las aldeas menudas (María de Carmen MARTín MARTín, El Cabildo catedralicio de Plasencia en la Edad Media. Estudio social, económico y administrativo, tesis 
comunales irá cambiando paulatinamente a lo largo de la segunda mitad del XV y del primer cuarto del siglo XVI. El Campo Arañuelo será una gran reserva de espacio para Plasencia, que intentará arrogarse su control exclusivo al margen de los derechos comunales de toda la tierra, incluidos los señoríos. Se crearán dehesas privadas, boyales y propios, con lo que se detrae espacio al libre aprovechamiento. Poco después de la señorialización de Plasencia, en 1444, esta ciudad amojona la dehesa de Torviscoso "para aver della dinero e provecho para poder sostener la gente de armas e costas que se fisieren en la guarda de la dicha çibdad e de sus terminos" y concede su renta al conde Pedro de Estúñiga ${ }^{47}$. En 1452, debido a "la grand neçesidad que esta çibdad esta e el menester que tiene para reparar la çerca e torres desta çibdad", deslinda las dehesas de San Benito, Espadañal y Cabeza del Toro ${ }^{48}$.

Los señoríos se van a oponer claramente a los intentos de Plasencia de disponer libremente de los comunales en función de sus necesidades o en beneficio de su señor jurisdiccional ${ }^{49}$. En septiembre de 1444 , todos salvo Jaraicejo destruyen los mojones de la dehesa de Torviscoso ${ }^{50}$. También se oponen a las dehesas creadas en 1452, siendo infructuosas sus demandas ante el conde Pedro de Estúñiga ${ }^{51}$. Al igual que antes, éste parece el gran beneficiario. En 1455, su hijo y sucesor Álvaro de Estúñiga arrendó las dehesas de San Benito y Espadañal en calidad de propietario ${ }^{52}$. Esta familia obtiene, de este modo, un patrimonio muy importante en la comarca ${ }^{53}$

Las sentencias contrarias a Plasencia no parecen que hayan supuesto una vuelta a la realidad anterior. Los Estúñigas conservarán algunas dehesas en el Campo Arañuelo pese a la sentencia de Diego González de Ciudad Real

doctoral inédita, Salamanca, 1999, pp. 234-7 y 272-289). El territorio que se extiende entre los ríos Almonte y Tajo también alberga mumerosas dehesas. No sucede lo mismo en las comarcas de montaña, donde parecen tener una importancia reducida.

${ }^{47} \mathrm{AHN}$, Nobleza, Frías, leg. 1246, s/n, f. 3 v. (respuesta de Plasencia a los señoríos, 16octubre-1444).

${ }^{48}$ AHN, Nobleza, Frías, leg. 1373, no 9.

${ }^{49}$ En relación con estas actuaciones, que contravenían usos asentados, resulta llamativo que Pedro de Estúñiga disponga en su testamento que "por quanto tome ciertas dehesas en el Campo de Arañuelo, termino de mi ciudad de Plasenciạ, las quales eștan señaladas e amojonadas, mando que se vea por justicia si lo sobredicho se podia hacer, e sy justicia no hera se desfaga e tornese en el estado que primero estava, e se pague lo que obe llevado dellas a quien lo abia de llevar de derecho" (Vicente PAREDES GUILLEN, Los Zúñiga, señores de Plasencia, "Revista de Extremadura", VII [1907], no 67, pp. 8-9).

${ }^{50}$ AHN, Nobleza, Frías, leg. 1246, s/n; documento de 8-septiembre-1444.

${ }^{51}$ AHN, Nobleza, Frías, leg. 1373, no 9, ff. 4 v.-5 r.

${ }^{52}$ AHN, Nobleza, Osuna, leg. 299, no 2-5.

${ }^{53}$ E.C. DE SANTOS, El siglo XV en Plasencia y su tierra, p. 132; Miguel Angel LADERO QUESADA, Rentas condales en Plasencia (1454-1488), "El siglo XV en Castilla. Fuentes de renta y política fiscal" Barcelona, 1982, p. 178, señala sobre las propiedades de esta familia que "las rentables". 
$(1451)^{54}$ y la ejecutoria de Enrique IV $(1460)^{55}$. En 1471, Álvaro de Estúñiga dona la dehesa de Espadañal ${ }^{56}$.

El desarrollo de los adehesamientos en el Campo Arañuelo va a continuar en la segunda mitad del siglo XV y principios del XVI. Plasencia y sus aldeas, no así los señoríos, se verán favorecidas. En 1515, se deslinda la dehesa nueva de los Caños o de San Minejo (quizás Martinejo; actual Seminejo), de la que desconocemos su origen preciso. Se alude a la dehesa del Centenillo "que es dehesa boyal de Malpartida y la Serradilla" ${ }^{57}$. En 1522, se señalan con autorización real las dehesas de Las Lomas, Miramontes y Pescadores como dehesas boyales de Plasencia. Los señoríos se oponen porque Plasencia "avia en el dicho canpo muchas dehesas boyeras que la dicha çibdad avia dado a muchos lugares de su tyerra e avia dado e alargado muchos exidos" ${ }^{28}$.

Este proceso de creación de dehesas comunes y privadas, de propios o de ampliación de ejidos se ha podido realizar por la abundancia de baldíos y comunales, sin duda un rasgo definitorio del Campo Arañuelo a lo largo del siglo XV. No deja de ser sintomático sobre esta realidad que algunos concejos, incluido el de Plasencia, dispongan en la zona de dehesas boyales pese a su relativa lejanía.

El espacio señorializado presenta rasgos diferentes. Aunque no conocemos con precisión sus estructuras socioeconómicas ${ }^{59}$, parece un territorio donde se ha realizado una más intensa apropiación y en el que las dehesas privadas han adquirido cierta importancia. Fernando de Monroy poseía a mediados del siglo XV las del Bote, Huerta y Peraleda, que lindada con los términos de la aldea del mismo nombre ${ }^{60}$.

A lo largo del siglo XV, el Campo Arañuelo se ha ido transformando. Fundamentalmente ha incrementado su base demográfica. En 1494, contaba

${ }^{54}$ AHN, Nobleza, Frías, leg. 1373, $\mathrm{n}^{\mathrm{o}} 8$.

${ }^{55}$ AHN, Nobleza, Frías, leg. 1369, no 9.

${ }^{56} \mathrm{AHN}$, Nobleza, Frías, leg. 1242, $\mathrm{n}^{\mathrm{o}} 7$.

${ }^{57}$ A. Cat. Plasencia, leg. 136, no 9, f. 2 v.

${ }^{58} \mathrm{~A}$. Mun. Plasencia s/n ${ }^{\mathrm{o}}$, doc. de 7-enero-1522.

${ }^{59}$ Sobre la formación y evolución de estos señoríos pueden consultarse: E. C. DE SANTOS, $E l$ siglo XV en Plasencia y su tierra, pp. 56-9 y 71-3; J. L. DEL PINO, Extremadura en las luchas politicas del siglo XV, Badajoz, 1991, pp. 94-107. Alfonso FRANCO SILVA. Oropesa. El nacimiento de un señorio toledano a fines del siglo XIV "La fortuna y el poder. Estudios sobre las bases económicas de la aristocracia castellana "s. XIV-XV)", Cádiz, 1996, pp. 135-154; Alfonso FRANCO SILVA y José Luis DEL PINO GARCÍA. El señorío de los Monroy (siglos XIII-XV), "Hernán Cortes y su tiempo", vol. 1, pp. 153-165; Nicolas ÁvILA SEOSANE, Monroyes, Botes y Almaraces: tres señorios tempranos en el concejo de Plasencia ,"En la España Medieval", 27 (2004), pp. 131-163. Estos trabajos se centran en los aspectos políticos-jurisdiccionales y en las familias señoriales.

${ }^{60} \mathrm{AHN}$, Nobleza, Frías, leg. 1249 , no 40-2, ff. 13 r.-15 v. No faltan informaciones anteriores que permiten sostener esta mayor difusión de las dehesas en el espacio señorializado: AHN, Nobleza, Frías, leg. 1249, $\mathrm{n}^{\circ} 2$, a. 1276; D. SÁNCHEZ LORO, Historias inéditas, placentinas, II, pp. 92-94, a 1292 "de Almaraz y de su termino, y de las dehesas que alli son"); Academia de la Historia, colección Salazar, L-10, ff. 141-143, a. 1317 (Almaraz). 
con casi 1.400 vecinos $^{61}$, en torno al $15 \%$ de la población de la tierra de Plasencia para un $23 \%$ del territorio. La comarca seguía estando comparativamente poco poblada, pero ya no podemos considerarla un territorio semidesértico.

No disponemos de datos para mediados del siglo $\mathrm{XV}$, cuando se desarrolla el pleito que nos ha servido de base para nuestro estudio, pero sin duda el proceso de crecimiento demográfico que está plenamente materializado en 1494 comenzó mucho antes, quizás en las primeras décadas del siglo. El incremento poblacional ha generado una problemática diferente ${ }^{62}$. Una explotación más intensa está en la base del enfrentamiento que se desarrolla entre Plasencia y las villas señoriales desde 1442.

Los derechos de las villas señoriales y el funcionamiento de toda la tierra de Plasencia como una unidad en la explotación de los comunales estaban plenamente constituidos a finales del siglo XIV. Un pleito entre Plasencia y Jaraicejo es ilustrativo sobre el particular. La realidad que refleja entendemos que se puede generalizar a las villas señoriales. En 1338, Alfonso XI ratifica una sentencia promulgada por el alcalde (¿del rey?) Gonzalo González y por el oidor Fernán Pérez. El primero falló que "los dejedes [a los vecinos de Jaraicejo] usar en vuestros terminos, segund que los otros vecinos y moradores de la tierra de ahi de Plasencia usan y deben usar; salvo finque a vos, el dicho concejo de Plasencia, que puedan ir con vusco en apellido o para en defendimiento de vuestro termino y pechar con vusco para hacer puentes o conpras en acrecentamiento de termino" ${ }^{63}$. La tierra de Plasencia se mantiene como una unidad en algunos aspectos. Todos sus vecinos, independientemente de su dependencia jurisdiccional, mantienen derechos equivalentes sobre el término.

El pleito sobre términos con Belvís, villa señorial arañuela, en 1376 nos ofrece, igualmente, una información de extraordinario interés. En la sentencia se falla que si "consintiesen a los vecinos de Plasencia pacer y labrar en la heredad del dicho donadio, segun lo hallaron por testigos que lo usaron hasta el tiempo de la dicha sentencia, que consintiendolo asi que el dicho Esteban Fernandes y sus herederos y los dichos sus vasallos que usasen y labrasen en la dicha tierra de Plasencia, segun lo usaron" ${ }^{4}$. Se mantienen derechos recíprocos de los vecinos de Belvís y Plasencia sobre los respectivos términos. No estamos ante una innovación sino ante un uso asentado.

Los dos casos citados nos hacen pensar que la señorialización de algunas aldeas placentinas no alteró los usos comunales, de modo que en ciertos aspectos se siguió funcionando como si el término fuera una unidad

${ }^{61}$ E. C. DE SANTOS, La historia medieval de Plasencia, pp. 100-1 (la población de Belvís se estima junto a sus aldeas, algunas de las cuales se situaban al sur del Tajo y por ello fuera del Campo Arañuelo).

${ }^{62}$ En todo caso, las tercias y alcabalas de 1454 muestran la reducida capacidad fiscal del Campo Arañuelo en relación con las demás comarcas placentinas (E. C. DE SANTOS, La historia medieval de Plasencia, pp. 271 y 275).

${ }^{63}$ D. SÁNCHEZ LORO, Historias placentinas inéditas, II, pp. 205-6.

${ }^{64}$ D. SÁnCHEZ LORO, Historias placentinas inéditas, II, p. 299. 
jurisdiccional con una sola vecindad. Esta circunstancia nos permite explicar que el Campo Arañuelo sea aprovechado indistintamente por vecinos de las aldeas placentinas y las villas señoriales a mediados del siglo XV.

Un factor a considerar en la explotación del Campo Arañuelo es la existencia de comarcas de montaña que han conocido una temprana ocupación y que todo hace indicar que mantienen una población importante, al menos en términos relativos, desde mediados del siglo XIV, coincidiendo con un pico demográfico previo a las pestes bajomedievales. Mientras estas comarcas han mantenido una escasa población el interés en otros espacios ha debido ser limitado. Conforme ha ido aumentando se han debido incrementar los vínculos con el Campo Arañuelo, con buenas posibilidades agrarias y pecuarias aunque presente algunos problemas ${ }^{65}$.

De este modo, el Campo Arañuelo tendría una población superior a la que revelan los escasos datos demográficos disponibles. Vecinos de otras comarcas dispondrían de una segunda residencia en la zona, quizás la primera en términos reales. Esta situación ha planteado diversos problemas que alcanzarán un nivel de ruptura en 1442. Pedro de Estúñiga va a estimular y amparar un intento de eliminar o reducir los derechos que mantienen las villas señoriales sobre el término placentino.

Debemos considerar para estudiar la comarca la existencia de tres tipos de componentes demográficos: los vecinos de las diversas aldeas y villas de la zona; los que tienen una segunda residencia durante una parte importante del año y disponen de explotaciones agropecuarias; y los que se desplazan a la comarca para el aprovechamiento de sus pastos y bellota. En conjunto, configuran una realidad compleja y diversa que difiere sensiblemente de los datos oficiales de vecindad. No estamos en condiciones de precisar el papel de los diversos componentes, aunque si de esbozar algunas ideas de interés.

A mediados del siglo XV, la población del Campo Arañuelo debía estar muy lejos de los casi mil quinientos vecinos de 1494. Quizás se situase en un punto intermedio entre la existente a principios y al final de este siglo (quinientos a setecientos vecinos). En relación con la doble vecindad, sabemos que veintiún vecinos de Jarandilla tenían una segunda residencia en el Campo Arañuelo ${ }^{66}$. Sin duda, esta villa es una de las poblaciones que ha contribuido en mayor medida a la explotación de la comarca. También debemos considerar a Valverde y sus aldeas, y al resto de las comunidades veratas, señorializadas o dependientes de Plasencia. El Valle del Jerte quizás tuviera un menor peso, pero el ejemplo de Tornavacas, que conocemos mejor por su condición señorial, seguramente no era excepcional. Importante debió ser el aporte de las comunidades situadas entre los ríos Almonte y Tajo. El resto de las comarcas tuvo seguramente una menor participación. En todo caso, la aportación de Jarandilla $(14,97 \%$ de la población verata en 1494) debió ser

\footnotetext{
${ }^{65}$ Justo CORCHÓn, El Campo Arañuelo (Estudio geográfico de una comarca extremeña), Madrid, 1963, pp. 97 y 179, considera como elementos negativos la insalubridad de las aguas y la abundancia de paludismo.

${ }^{66} \mathrm{AHN}$, Nobleza, Frías, leg. 1369, n 4, f. 5 r.
} 
significativa aunque minoritaria. Parece razonable pensar que a mediados del siglo XV, el fenómeno de la doble vecindad podría afectar a más de un centenar de pobladores, quizás a dos. Se trata, en todo caso, de un componente relativo muy importante en comparación con la población de la comarca.

Estos pobladores que disponen de explotaciones de corte agropecuario posiblemente no constituyen el componente más importante entre los foráneos que realizaban diversas actividades económicas en la zona. Debían ser mucho más numerosos aquéllos que de forma estacional llevaban allí sus ganados. La mayor parte de los testigos del interrogatorio de 1451 no residen en el Campo Arañuelo aunque lo conocen bien. Sólo disponemos de unos pocos datos precisos sobre los vecinos de otras comarcas que aprovechaban sus pastos. En 1442 , treinta y nueve propietarios de Jarandilla llevan sus cerdos al Campo Arañuelo (siete de ellos tenían una segunda residencia en la comarca); en 1447 , lo hicieron veintitrés (tres con una segunda residencia) ${ }^{67}$. En conjunto, sumaban entre las mil quinientas y las dos mil cabezas ${ }^{68}$. Del mismo modo, vecinos de prácticamente todas las aldeas o villas de la Vera, el Valle del Jerte y la zona Almonte-Tajo traían ganado a la comarca. Las prendas ganaderas documentadas entre 1442 y 1451 son ilustrativas, pese a que no siempre se precisa la vecindad. Afectan a las siguientes poblaciones veratas: Losar (cinco vecinos), Valverde (ocho), Jarandilla (cinco sin computar los de 1446, alrededor de una treintena), Pasarón (cinco), Arroyomolinos (uno) y Collado (uno). Las demás comarcas están menos representadas: se prenda a nueve vecinos de Tornavacas (Valle del Jerte) y dos de Jaraicejo (Almonte-Tajo). Por tanto, y dentro de una estimación modesta, al Campo Arañuelo podrían desplazarse, especialmente durante la montanera, algún centenar de propietarios y bastantes miles de cerdos. Esta comarca era a mediados del siglo XV una auténtica reserva ganadera para toda la tierra de Plasencia. Miles de cabezas y algunos centenares de propietarios se convertían en parte fundamental de la explotación y aprovechamiento económicos de la zona.

A la ganadería de otras comarcas hay que añadir la autóctona, formada como hemos visto por cerdos y ovejas. Debido a su escasa población, esta cabaña sería más modesta, aunque en absoluto despreciable. Los datos relativos a Almaraz, Belvís y Serrejón, de carácter parcial, denotan una importancia de la ganadería similar a la que se puede documentar en Jarandilla.

En conjunto, a mediados del siglo XV el Campo Arañuelo sostiene una importante ganadería estante y riberiega, proveniente de las diversas comarcas placentinas (Valle, Vera y Almonte-Tajo especialmente) ${ }^{69}$. Muy

\footnotetext{
${ }^{67} \mathrm{~J}$. Clemente, La ganadería porcina de Jarandilla de la Vera, p. 744.

${ }^{68}$ J. CLEMENTE, La ganadería porcina de Jarandilla de la Vera, p. 749 (años 1442 y 1447); AHN, Nobleza, Frías, leg. 1369, no 5, f. 2 v. (año 1446).

${ }^{69}$ Frente a las cabañas provenientes de las diversas comarcas de la tierra placentina, el ganado trashumante o de otras jurisdicciones parece tener una importancia secundaria. En el interrogatorio de 1451 aparecen vecinos de Barco de Avila o Puente del Arzobispo como pastores o testigos, pero no se precisa explícitamente que traigan ganado (AHN, Nobleza, Frías, leg. 1367, n ${ }^{\circ} 1$, ff.' $159,202,204$ v. y 351 v.-352 v.). La información sobre la explotación de las dehesas es muy
} 
posiblemente estamos ante el sector económico de mayor peso. Durante mucho tiempo miles de cabezas de las diversas especies compartieron el aprovechamiento indicado y, posteriormente, lo seguirían haciendo fuera de las fechas otoñales reservadas a los cerdos.

La actividad económica de la comarca, por tanto, no puede entenderse a partir de su escasa población oficial. Habitualmente, de forma estacional o a lo largo de la mayor parte del año, muchos vecinos de otras comarcas permanecían en el Campo Arañuelo tanto para realizar aprovechamientos ganaderos como agropecuarios. La explotación de la comarca era mucho más intensa de lo que cabría suponer de su limitada población.

\subsection{Señorialización de Plasencia y derechos comunales (1442-c. 1451)}

Plasencia, que ha visto desarrollarse diversos señoríos en su jurisdicción, es donada en 1442 a Pedro de Estúñiga. Durante algo menos de medio siglo, esta ciudad deja de pertenecer al realengo y va a formar una de los señoríos más importantes de la región. Para el Campo Arañuelo, la fecha reseñada está llena de significación. El aterrizaje de nuevos señores jurisdiccionales en Extremadura en el segundo cuarto del siglo XV (Galisteo, Medellín, la misma Plasencia) va unido a una intensa conflictividad ${ }^{70}$. Su actuación persigue maximizar sus ingresos y proveerse de una sólida base solariega. En el caso de los Estúñiga, la situación placentina es muy particular. Se trata de un territorio con numerosas villas señoriales que detentan derechos importantes sobre los espacios comunales. La actuación contra estos señoríos, para los cuales el Campo Arañuelo era fundamental, es algo que une a los señores y a la propia ciudad. Se va a marcar una diferencia entre la situación anterior y posterior a 1442. Estamos ante un conflicto que se va a mantener a lo largo de todo el siglo y que continuará después de la vuelta de Plasencia al realengo. Sin duda, un factor a considerar en este nuevo

limitada. Las de San Benito, la Macana y Espadañal, de los Estúñiga, fueron arrendadas en 1455 a Juan de Oviedo, "vezino de Plasençia y Bejar" (ẢHN, Nobleza, Osuna, leg. 299, n ${ }^{\circ}$ 2-5, f. 3 r.); la dehesa de Herguijuela aparece a mediados del XV V arrendada a vecinos de Tornavacas siendo destino preferente de las vacas de esta localidad (AHN, Nobleza, Frías, legs. 1369, n⿳亠口冋口. 7, f. 6 r., y 1367, n ${ }^{\circ} 1$, f. 289 v.). El ganado trashumante, y en general el de fuera de la tierra de Plasencia, parece tener un papel secundario en el Campo Aranuelo.

${ }^{70}$ A. FRAnCo y J. L. DEL PINO, El Campo de Arañuelo en el siglo XV, pag. 211, consideran que el acceso de los Estúñiga a la jurisdicción placentina abré una etapa especiălmente conflictiva con los señoríos de la tierra. Esta circunstancia también es percibida por Juan Sanchez del Espinar, vecino de Tornavacas, que señala sobre el aprovechamiento del Campo Arañuelo "que en tienpo que la çibdad era del señor rey e de la señora reyna que davan de cada hato a los arrendadores del verde un queso e veynte e cinco maravedis, e que agora que llievan lo que quieren, e dixo que esto que dicho ha de los dichos un queso e veynte e çinco maravedis que lo davan a los arrendadores por abenencia que con ellos fasian e que sy no ramoneavan ni cortavan rama que les no davan cosa alguna ni lo demandavan, e que agora despues que la cibdad es del conde que agora corten rama o non que llevan quanto quieren e pueden" (AHN, Nobleza, Frías, leg. 1367, n 1 , f. 286 v.). La oligarquía señorial residente en Plasencia o la propia catedral también se verán afectadas por la nueva situación: D. SÁnCHEZ LORO, Historias inéditas placentinas, II, p. 410; Gloria LORA SERRANO, Conflictividad eclesiástica y conflictividad social en Plasencia y su tierra a fines de la Edad Media, "Historia. Instituciones. Documentos", 31 (2004), pp. 383-386. 
contexto es una coyuntura económica caracterizada por un importante crecimiento demográfico y un aumento del espacio cultivado ${ }^{71}$. Los derechos sobre los comunales de las villas señoriales tenían un significado muy diferente en el momento de la repoblación o en el siglo XIV y en los siglos XV ó XVI. Hay que considerar que las normativas se aplican de forma indistinta a los señoríos, la propia ciudad y sus aldeas.

A partir de 1442, Plasencia va a aprobar diversas ordenanzas que afectan de modo decisivo al aprovechamiento del Campo Arañuelo. Como cabeza del territorio, va a considerar que puede legislar no sólo para sus aldeas sino también para los señoríos y, por ello, alterar y cambiar los usos establecidos. Esta posición unilateral va a profundizar las diferencias. No parece casual que esta dinámica haya que vincularla con los nuevos señores de Plasencia, los Estúñigas, que avalan y sostienen estas decisiones frente a las reclamaciones de las villas señoriales ${ }^{72}$.

En ningún momento Plasencia intenta negar el derecho de los señoríos a acceder a los pastos del Campo Arañuelo, pero es muy posible, y no faltan indicios, que la actuación de los guardas haya incidido de modo preferente sobre los vecinos de estos lugares. Al margen de que los señoríos no estén de acuerdo con las nuevas ordenanzas, no son tanto las normas como su aplicación lo que parece marcar una diferencia fundamental. Conocemos de modo indirecto, a través de la contestación de Plasencia a los señoríos, una ordenanza u ordenanzas de 1442 . Esta ciudad impuso una tasa o tributo a todos los ganados que pastaban en el Campo Arañuelo. Sostiene la convenien-

${ }^{71} \mathrm{La}$ primera mitad del siglo XV presenta en la corona de Castilla evidentes signos de recuperación y/o crecimiento: José Ramón DÍAZ DE DURANA Alava en la baja Edad Media. Crisis, recuperación y transformaciones socioeconómicas (c.1250-1525), Vitoria, 1986, pp. 148151 y El mundo rural guipuzcoano al final de la Edad Media: progreso agrícola, gestión y explotación de la tierra, "En la España Medieval", 21 (1998), p. 73; José Ångel GÁACÍA DE CORTÁZAR et al., Bizcaya en la EdadMedia. Evolución demográfica, económica, social y política de la comunidad vizcaína medieval, 3 vols., San Sebastián, 1985 ., vol. I, p. 262; Miguel Angel LADERO QUESADA, El crecimiento económico de la Corona de Cástilla en el siglo XV: ejemplos andaluces, en Los mudejares de Castilla y otros estudios de historia medieval andaluza, Granada, 1989, p. 26; Miguel Angel LADERO QUESADA et al., Diezmo eclesiástico y producción de cereales en el reino de Sevilla (1408-1503), Sevilia, 1979, p. 45; Mercedes BORRERO FERNÁNDEZ, El mundo rural sevillano en el siglo XV: Aljarafe y'Ribera, Sevilla, 1983, pp. 186189: Miguel RODRÍGUEZ LLOPIS, Señoríos y feudalismo en el reino de Murcia. Los dominios de la Orden de Santiago entre 1440 y 1515, Murcia, 1984..pp. 72-73; María Xosé RoDRÍGUEZ GALDO, Señores y campesinos en Galicia. Siglos XIV-XVI, Santiago, 1976, pp. 37-9; Hilario CASADO ALONSO, Señores, mercaderes y campesinos. La comarca de Burgos a fines de la Edad Media, Madrid, 1987, pp. 143-7; Francisco Javier GoICOLEA JULIÁN, Haro: una villa riojana del linaje Velasco a fines del Medievo, Logroño, 1999 . pp. 77-81; José Luis MARTín MARTín, El patrimonio de la Catedral de Salamanca. Un estudio de la ciudad y el campo salmantino en la baja Edad Media, Salamanca, 1985, p. 339; María Jesús SUÁREZ ALVAREZ, La villa de Talavera y su tierra en la Edad Media (1369-1504), Oviedo, 1982, pp. 318-20. La situación extremeña, pendiente de un estudio de conjunto, se ajusta a la pauta general. Entre $1403 \mathrm{y} 1440$ se conceden o amplian dehesas boyales en los maestrazgos de Alcántara o Santiago: Bernabé CHAVES, Apuntamiento legal sobre el dominio solar de la orden de Santiago en todos sus pueblos, Madrid, 1740 , ff. 61 v. y 173 v.-174 r.; Alonso de TORRES Y TAPIA, Cronica de la Orden de Alcántara, 2 vols., Madrid, 17633, vol. II, pp. 256 y 262; por otro lado, la incidencia que esta coyuntura de recuperación y crecimiento tuvo en el bosque se empieza a documentar claramente a partir de 1450: J. Clemente Ramos, La evolución del medio natural, p. 23.

${ }^{72} \mathrm{El}$ conde Pedro de Estúñiga se opuso a la ejecución de la sentencia de Diego González de Ciudad Real de 1451 y desoyó las peticiones de las villas señoriales para no contribuir en el mantenimiento de las murallas de Plasencia (AHN, Nobleza, Frías, leg. 1373, no 9, ff. 4 v.-5 r. y 7 , septiembre de 1452). No cuesta adivinar actuaciones similares con anterioridad. 
cia del mismo porque "esta muy destroyda e muy despoblada [Plasencia], caydas las çercas e puentes e ha mester muchos reparos, otrosi para desenajenar los propios e tierras e jurisdiçiones que estan enejenadas e por fuerça tomadas atreviendose los tales husurpadores de subir con las tales fuerças e tomas que tienen fecha esta çibdad ha mester de tornar sobre sy e de reparar lo mal reparado e caydo" ${ }^{\text {"73 }}$. Estamos ante dos elementos diferentes: recuperación de espacios apropiados indebidamente y reparación de los muros de la ciudad. Mientras el primer concepto justificaría la contribución de los señoríos por ser igualmente beneficiarios y usuarios, lo segundo compete exclusivamente a Plasencia y, en todo caso, a sus aldeas. Por otro lado, ahora se reserva la bellota de la comarca a los cerdos, prohibiéndose su aprovechamiento por vacas, ovejas u otros animales. Igualmente, se retrasa el uso de aleros quince días después de San Miguel (29 de septiembre) ${ }^{74}$.

Estas medidas, y sólo conocemos la actuación de los señoríos, sólo debieron general una oposición larvada ${ }^{75}$. Hay que considerar que en parte se deben a la necesidad de regular de modo más estricto un recurso crecientemente escaso en una coyuntura marcada por el crecimiento demográfico y agrario. En 1443, también Jarandilla redacta unas ordenanzas sobre los castañares de las que desconocemos su contenido, pero que sin duda supondrían una regulación más estricta de su aprovechamiento ${ }^{76}$. Losar de la Vera recibió una dehesa boyal en 1427 y la de Pasarón se amplió en $1428^{77}$.

Los señoríos se opusieron abiertamente a la creación de la dehesa de Torviscoso (c. 1444), que se detraía de este modo al aprovechamiento común. Alfonso Martínez, alcalde de Oropesa, indica que "puede aver siete años poco mas o menos tienpo... que el conde don Pedro Destuñiga que queria dehesas e faser dehesas en el canpo e montes de Arañuelo, e que era en perjuysio de las villas de los señorios que son en la comarca de la dicha çibdad de Plasençia; para resistir las dichas dehesas que por mandado de Garçia Alvares señor de Oropesa, que a la sason era bivo, que se allego gente de armas asy del dicho Garçia Alvares commo de otros señores en Belvis e en Almaras"78.

\footnotetext{
${ }^{73}$ AHN, Nobleza, Frías, leg. 1373, no 3, ff. 26 v.-27 r.

${ }^{74} \mathrm{AHN}$, Nobleza, Frías, leg. 1373, $\mathrm{n}^{\mathrm{o}} 3$, ff. 24 r. -26 r.

${ }^{75}$ Es posible que no se fuera muy estricto en la aplicación de estas normas. No se documenta la realización de ninguna prenda. En 1446, los señoríos aluden a "çiertas ordenanças e estatutos que disen antiguamente aver fecho e ordenado e agora de nuevo establesido, cerca de los pasos e landes e vellotas de los montes e canpos de Arañuelo", lo que abre la posibilidad a una vigencia temporalmente limitada (AHN, Nobleza, Frías, leg. $1369, \mathrm{n}^{\circ} 1$, f. 1 v.).

76 "estan unas ordenancas que hizo Jarandilla cerca de los castaños y castañares y verde dellos, año de 443" (AHN, Nobleza, Frías, leg. 1369, n⿳ 36, f. 7 V.). La información es especialmente rica para la tierra de Plasencia, donde a mediados del XV se está gestando una importante transformación normativa que rompe con prácticas silvícolas muy agresivas (J. CLEMENTE La

${ }^{77}$ D. SÁNCHEZ LORO, Historias inéditas placentinas, III, pp. 397 y 406.

${ }^{78} \mathrm{AHN}$, Frías, $1367, \mathrm{n}^{\circ}$ 1, f. 450 ; continúa indicando que "dende a poco tienpo que partieron de la dicha villa de Oropesa dies e nueve cavallos de la gineta e que fueron al dicho canpo de Arañuelo para resistir a Garçia Sanches de Caçeres e a otros que se desia que andavan en el dicho canpo de Arañuelo amojonando e fasiendo dehesas en perjuysio de las dichas villas de los señorios" (Ibíd., f. 450 v.).
} 4). 
Se vive una situación de enfrentamiento que implica no sólo a las comunidades afectadas sino a sus autoridades jurisdiccionales, aspecto sobre lo que sólo conocemos detalles muy puntuales. En todo caso no parece que se haya llegado a un conflicto generalizado. En contraposición a la reacción que suscitó la creación de la dehesa de Torviscoso, los cambios normativos se han recibido a lo que parece con cierta pasividad.

Se desarrollan en 1442, por tanto, unas formas de aprovechamiento más restrictivas, consecuencia probable de una mayor presión sobre el Campo Arañuelo en un contexto de desarrollo demográfico y agrario. En 1446, Plasencia redacta unas nuevas ordenanzas que van a tener un impacto enorme en el aprovechamiento de la comarca ${ }^{79}$. La oposición de los señoríos fue total. En septiembre de ese mismo año, poco después de la redacción de la ordenanza, Jarandilla y Tornavacas sostienen "que nosotros nunca tales ordenanças vymos ni oymos desir, por ende nuestra yntençion es de non faser mandamiento de como siempre fue e es costunbre de luengos tienpos aca, e que non dexaremos de usar commo sienpre usamos" ${ }^{\circ 0}$. En octubre, los señoríos, a excepción de Jaraicejo, deciden "que las dichas ordenanças no se deven guardar ni conplir, e por nos fueron espresamente contradichas" ${ }^{\text {. }}$. Ahora, además de reservarse el Campo Arañuelo a los puercos entre San Miguel y Navidad, lo que no deja de ser una repetición de lo ya aprobado en 1442, se toman dos decisiones de enorme impacto para los señoríos: se prohíbe el aprovechamiento de los pastos a aquéllos que tienen una doble vecindad y se obliga a que los diversos propietarios inscriban personalmente en Plasencia los puercos que van a llevar a la comarca.

La primera normativa afecta de modo exclusivo a los señoríos, puesto que los habitantes de las aldeas disfrutaban, en su caso, de una doble vecindad permitida. Por otro lado, la inscripción personal e individual en Plasencia suponía para los pequeños propietarios un coste inasumible ${ }^{82}$. Muy posiblemente, cambio la estructura de las cabañas porcinas que se desplazaban a la zona. En Jarandilla, en las listas de los cerdos de 1442 y 1447, ya analizadas, se aprecia una reducción del número de propietarios y la desaparición de los más modestos.

Los señoríos se van a oponer radicalmente al nuevo marco normativo. Las prendas y los apresamientos documentados no dejan lugar a dudas de su estricta aplicación y de la rebeldía abierta de las villas señoriales y sus vecinos. Su impacto sobre el aprovechamiento de la comarca ha debido ser elevado. En diciembre de 1446, Plasencia se dirige a Jarandilla en relación

${ }^{79}$ Han sido publicadas y estudiadas por A. FRANCO y J. L. DEL PINO, El Campo de Arañuelo en el siglo $X V$, pp. 215-217. La nueva signatura del documento es AHN, Nobleza, Frías, leg.
$1365, \mathrm{n}^{\circ} 1$.

${ }^{80} \mathrm{AHN}$, Nobleza, Frías, leg. 1373, no 2 , f. 8 v.

${ }^{81}$ AHN, Nobleza, Frías, leg. 1369, no 1, f. 2 r.

82 “a un ome oyo desir que llevara a escrivir dos puercos desde quatro leguas e que gastava en ellos tanto como pudiera gastar en criarlos en su casa, e que por esta manera yvan tọdos los pobres, e viudas, e huerfanos que puercos tenian a los escrevir, e que dello se les seguia grand daño" (AHN, Nobleza, Frías, leg. 1367, no 1, f. 340 v.). 
con las transgresiones de sus vecinos. No han respetado la reserva del Campo Arañuelo para los cerdos de San Miguel a Navidad, introduciendo además "vacas e novillos e ovejas e carneros e cabras e cabrones", ni las nuevas normas de inscripción del ganado porcino; posiblemente, tampoco han respetado la prohibición de usar aleros hasta quince días después de San Miguel $^{83}$.

La oposición a la inscripción individual de los cerdos se mantuvo bastante tiempo. En 1447, un año después de la ordenanza, Jarandilla elabora la lista conjunta del ganado porcino de la localidad que se desplazará al Campo Arañuelo y solicita, infructuosamente, que se asiente "en el libro donde todos los otros puercos de la dicha çibdad de Plasençia e su tierra se asentavan, por quanto asy era uso e costunbre en los años pasados" ${ }^{84}$. La oposición de algunos concejos a la nueva normativa no impidió su implantación y cumplimiento ${ }^{85}$. Tanto los señoríos como las aldeas placentinas se verán igualmente afectados. También se prenda a vecinos de estas últimas. Así sucede en 1450 con Pedro Sánchez de Torrecilla, vecino de Jaraíz, que inscribió tarde sus cerdos ${ }^{86}$.

La doble vecindad es otro campo de fricción. Suponía una utilización extrema de los derechos comunales, con una residencia real distinta de la oficial, y en determinados casos una pérdida de derechos para Plasencia en beneficio de las villas señoriales. La actuación de esta ciudad será decidida, con apresamientos y avecindamientos forzosos. La ordenanza aprobada en septiembre de 1446 para regular la explotación del Campo Arañuelo prohíbe la doble vecindad: "fue ordenado y guardado que los que tienen dos vesindades o mas que non puedan entrar nin comer con sus ganados en los terminos de la dicha çibdad e su tierra... que... los que toman las tales vesindades las toman a dapnos e non provechos de los tales lugares donde las toman, mas fasenlo por sus provechos singulares e dapno de la republica, ca por çient mrs. que da, o mas o menos, quieren pasar e comer con sus ganados mas que monta treynta veses lo que dan". Se precisa que, en lo sucesivo, "han de venir aqui a esta çibdad a tomar la dicha vesindad del conçejo, justicia e regidores de la dicha çibdad, segun la costumbre e ordenança antigua desta çibdad", debiendo señalar luego "en qual lugar o señorio dende el termino de la dicha çibdad quiere bevir e ser vesino e entonçes vaya a qual lugar, qui ser a bevir e continuar su vesindad, con tanto que despues que aquella tomare non tenga otra ninguna vesindad" ${ }^{87}$.

\footnotetext{
${ }^{83} \mathrm{AHN}$, Nobleza, Frías, leg. 1369, no 5, f. 2; se indica entre las transgresiones "varear e desmochar las ensinas, e alcornoques, e robles, e otros arvoles de los dichos nuestros montes e canpos de Arañuelo", lo que quizás esté relacionado con lo último que hemos señalado.

${ }^{84} \mathrm{AHN}$, Frías, $1367, \mathrm{n}^{\circ}$ 1, f. 388 r.; la lista de cerdos, Ibíd., ff. 385 v.-387 v.

${ }^{85}$ Fernán Sánchez, vecino de Cuacos, se desplazó en 1450 a Plasencia para inscribir sus cerdos personalmente (AHN, Frías, 1367, $\mathrm{n}^{\circ} 1$, f. 189 v.; también, f. 340 v.).

${ }^{86}$ AHN, Frías, 1367, no 1 , ff. 298 v.-299 r.

${ }^{87}$ A. FRANCO y J.L. DEL PINO, El Campo de Arañuelo en el siglo XV, p. 216.
} 
La aprobación de esta ordenanza va unida a una actuación decidida. En el mismo mes de septiembre o en octubre ya se habían realizado diversos apresamientos. Juan Sánchez Berrocoso y Fernán Martín Torés en un escrito que presentan el 12 de octubre en La Corcha aluden a las prendas realizadas por Juan Rodríguez de Cabañas, morador en Valparaíso, y Alonso García, arrendadores del salín y de la soldada del juez de Plasencia en 1446, a vecinos de Jarandilla "que tyenen sus labranças e crianças en los montes e canpos de Arañuelo en Torvyscoso, e en La Corcha, e en San Benito, e en otros qualesquier lugares e labranças e crianças del dicho canpo e montes de Arañuelo" $"$. Unos días antes, los procuradores de Jarandilla solicitan al escribano Luis García que haga constar la existencia de una fe pública en donde se precisa que los vecinos de esta villa que tienen "labranças e crianças en el canpo e montes de Arañuelo" contribuyen en todos los pechos concejiles, "asi en puentes, como en fuentes, e en todos los pechos reales e conçejiles e del dicho señor, e en salinas, e marteniegas, e en todos los otros pechos e tributos e derramas que en la dicha villa se han acaesçido e acaesçe a derramar e repartir e pagar en cada año" ${ }^{89}$. Estos vecinos de Jarandilla pretenden basar sus derechos en su condición de contribuyentes fiscales en esta villa señorial, algo que está en la base del rechazo placentino, ante la falta de coincidencia entre contribución fiscal -única- y residencia -doble-.

El problema de la doble vecindad seguía vigente hacia mediados del siglo XV. Plasencia no logra romper pese a su actuación un uso muy arraigado. En 1449, seguramente en noviembre, se realizan apresamientos de vasallos señoriales por este motivo. El alguacil Pedro de Bañuelos apresa en Torviscoso, La Corcha y San Benito a Alfonso Jiménez, Martín Sánchez Berrocoso, Juan Sánchez de La Corcha (quizás igualmente de las Zahurdas), Diego García, y Fernán Martín Torés, vecinos de Jarandilla; este mismo año también se apresó seguramente a Gonzalo Martín Torés y Miguel Sánchez Conejero $^{90}$. En 1454, treinta y cinco vasallos de Garcí Álvarez y del conde Pero Niño residían en diversas aldeas de la comarca ${ }^{91}$.

Plasencia continuó con sus cambios normativos. El 25 de octubre de 1450, el conde Pedro de Estúñiga y el concejo placentino acuerdan establecer un tributo sobre "el pasto e vellota" del Campo Arañuelo para "faser reparar la dicha çerca de la dicha çibdad por la mejor manera que reparar se pudiese", consistente en quince maravedís por yegua o potro, ocho por cabeza de ganado vacuno, dos por ovina o caprina, seis por puerco y cuatro por

\footnotetext{
${ }^{88} \mathrm{AHN}$, Nobleza, Frías, leg. 1369, no 4, f. 3 v.

${ }^{89} \mathrm{AHN}$, Nobleza, Frías, leg. 1369, $\mathrm{n}^{\mathrm{o}} 4$, f. 5.

${ }^{90}$ AHN, Nobleza, Frías, leg. 1365, no 2 , y leg. 1367, no 1 , ff. 197 r. y 200 v. (se alude a un Domingo 'García de San Benito, pero quizás sea el mișmo Diego García, también de esta localidad). Ignoramos cuando se'llevó a cabo el apresamiento de tres vecinos de Tornavacas, realizado entre otros por los escuderos placentinos Fernando de Avellaneda y Diego de Aguetes (AHN, Nobleza, Frías, leg. $1369, n^{\circ} 2$, f. 11 r.). No sabemos si se realizaron más apresamientos, pero en la sentencia de Diego González de Ciudad Real de 1451 sólo se alude a algunos vecinos de Jarandilla, ya citados, apresados en 1449 (AHN, Nobleza, Frías, leg. 1373, n 8 8, f. 3 r.).

${ }^{91}$ M.A. LADERO, Rentas condales en Plasencia, p. 174.
} 
cochino $^{92}$. Ignoramos la suerte que corrió el que se estableció o intentó establecerse en 1442, pero ahora se va a intentar cobrar de forma sistemática. Se dispone, para facilitar la recaudación, "que cada conçejo se prendase çiertos puercos por todo el dicho tributo que copiese a todos los puercos de los vesinos del tal conçejo" ${ }^{93}$. Esta normativa permitía, pese a su clara ilegalidad, la realización de prendas indiscriminadas por el impago propio o de otros convecinos. Los recaudadores realizaron su trabajo con celo desde el mismo momento de la aprobación de la nueva ordenanza, desarrollando diversas actuaciones en octubre y noviembre ${ }^{94}$. Prendaron los puercos de Alfonso Martínez Flores, vecino de Jarandilla, "disiendo que les llevavan por la yerva e lande que avian comido todos los puercos de Jarandilla, porque no les pagavan el tributo e inpusiçion que a cada cabeça de ganado avian echado" ${ }^{95}$. Igualmente, Álvaro y Pedro de Bañuelos, entre otros, llevaron veintiocho puercos a Alfonso Martínez Cucharero y Fernán Sánchez el Viejo, vecinos de Serrejón, "por la yerva que avian de pagar los vesinos de la dicha villa de Serrejon de los ganados del dicho lugar" ${ }^{26}$. En 1450, tomaron a Alfonso Sánchez de Salamanca cien puercos y "le dixeron que le tomavan todos sus puercos por el tributo e ervaje que le cabia pagar a todo el conçejo de Pasaron" $"$. Muchas de las prendas realizadas en el otoño de 1450 ó principios de 1451, y que supusieron para algunos propietarios la perdida de todo su ganado porcino, estuvieron relacionadas posiblemente con el nuevo tributo y su particular forma de recaudación. Es llamativo que sólo se realicen sobre vasallos señoriales.

Desde 1442, coincidiendo con la señorialización de la ciudad, Plasencia realiza diversas actuaciones que inciden en la forma de aprovechamiento del Campo Arañuelo. Esta dinámica va a ir profundizando las diferencias con las villas señoriales. Aunque los cambios normativos afectan igualmente a las aldeas placentinas, algunos aspectos chocan específicamente con los derechos de aquéllas. Plasencia intenta imponer el principio de que todos los que acceden a la explotación del Campo Arañuelo deben contribuir en determinadas obligaciones y de que, como única propietaria del mismo, puede regular libremente su aprovechamiento. Las villas señoriales consideran que esta ciudad no tiene ningún derecho exclusivo y que la potestad normativa la comparten todas las unidades jurisdiccionales del término.

Las sentencias que se suceden a partir de 1451, empezando por la de Diego González de Ciudad Real, consideran que los cambios normativos realizados por Plasencia desde 1442, coincidiendo con su entrega a los

\footnotetext{
${ }^{92}$ AHN, Nobleza, Frías, leg. 1366, no 2, f. 390 r.

${ }^{93} \mathrm{AHN}$, Nobleza, Frías, leg. 1366, no 2, f. 390 v.

${ }^{94} \mathrm{En}$ un escrito de requerimiento realizado por los concejos de señorío el 13 de noviembre de 1450 se alude a numerosas prendas de ganado (AHN, Nobleza, Frías, leg. 1373, n 4, f. 5 r.).

${ }^{95} \mathrm{AHN}$, Nobleza, Frías, leg. 1367, no 1, f. 245; igualmente, f. 246 r.

${ }^{96} \mathrm{AHN}$, Nobleza, Frías, leg. 1367, n ${ }^{\text {0 }} 1$, f. 341 r.; igualmente, 343 v. y 348 r.

${ }^{97}$ AHN, Nobleza, Frías, leg. 1367, no 1, f. 333 r.
} 
Estúñigas, no respetan los derechos de las villas señoriales ${ }^{98}$. La sentencia citada anula las nuevas normativas relativas a la saca de pan, la explotación de los pinares, la bellota, la inscripción de los puercos o la doble vecindad ${ }^{99}$. En todo caso, 1442 marca el comienzo de una nueva problemática en el aprovechamiento del Campo Arañuelo vinculada a una ocupación más intensa y una mayor competencia por los recursos.

\section{CONCLUSIONES}

El Campo Arañuelo placentino se presenta a mediados del siglo XV con un perfil muy definido caracterizado por una débil ocupación y la abundancia de zonas baldías susceptibles de un aprovechamiento agrario y pecuario. Todo ello ha generado una serie de relaciones bien definidas con otras comarcas del extenso término de Plasencia, relaciones que nos han permitido ahondar en algunos elementos de su vida rural. Muchos propietarios de ganado y vecinos de otras localidades tienen aquí una segunda residencia. Se unen a la escasa población existente para desarrollar, sin embargo, una intensa explotación de la zona.

Posiblemente, esta dinámica de complementariedad intercomarcal ha adquirido mayor importancia conforme una población creciente ha generado una claro déficit cerealista en las zonas de montaña. Todo ello ha abierto el camino a la doble vecindad, el alquiler de bueyes o el desplazamiento de asalariados para la siega (mesiego). Las relaciones indicadas no podrían haberse materializado sin el funcionamiento de todo el término de Plasencia, al margen de la dependencia jurisdiccional, como una unidad en el aprovechamiento de los espacios comunales. Esto significa que esta ciudad, sus aldeas y las villas señoriales participan conjuntamente en la explotación de los montes y baldíos.

El crecimiento agrario y demográfico del siglo $\mathrm{XV}$, que ha debido aumentar el interés en el Campo Arañuelo, y la señorialización de Plasencia en 1442 están en la base de importantes cambios normativos que, entre otras cosas, limitan los derechos de los vecinos de los señoríos. Estamos ante un conflicto de larga duración que las sentencias judiciales no aciertan a solucionar.

Fecha de recepción del artículo: junio 2007.

Fecha de aceptación y versión final: diciembre 2008.

\footnotetext{
${ }^{98} \mathrm{AHN}$, Nobleza, Frías, leg. 1373, $\mathrm{n}^{\circ} 8$.

${ }^{99}$ Sobre éstas y otras sentencias sucesivas, cf. A. FranCO y J.L. DEL PINO, El Campo de Arañuelo en el siglo XV, pp. 212-3.
} 



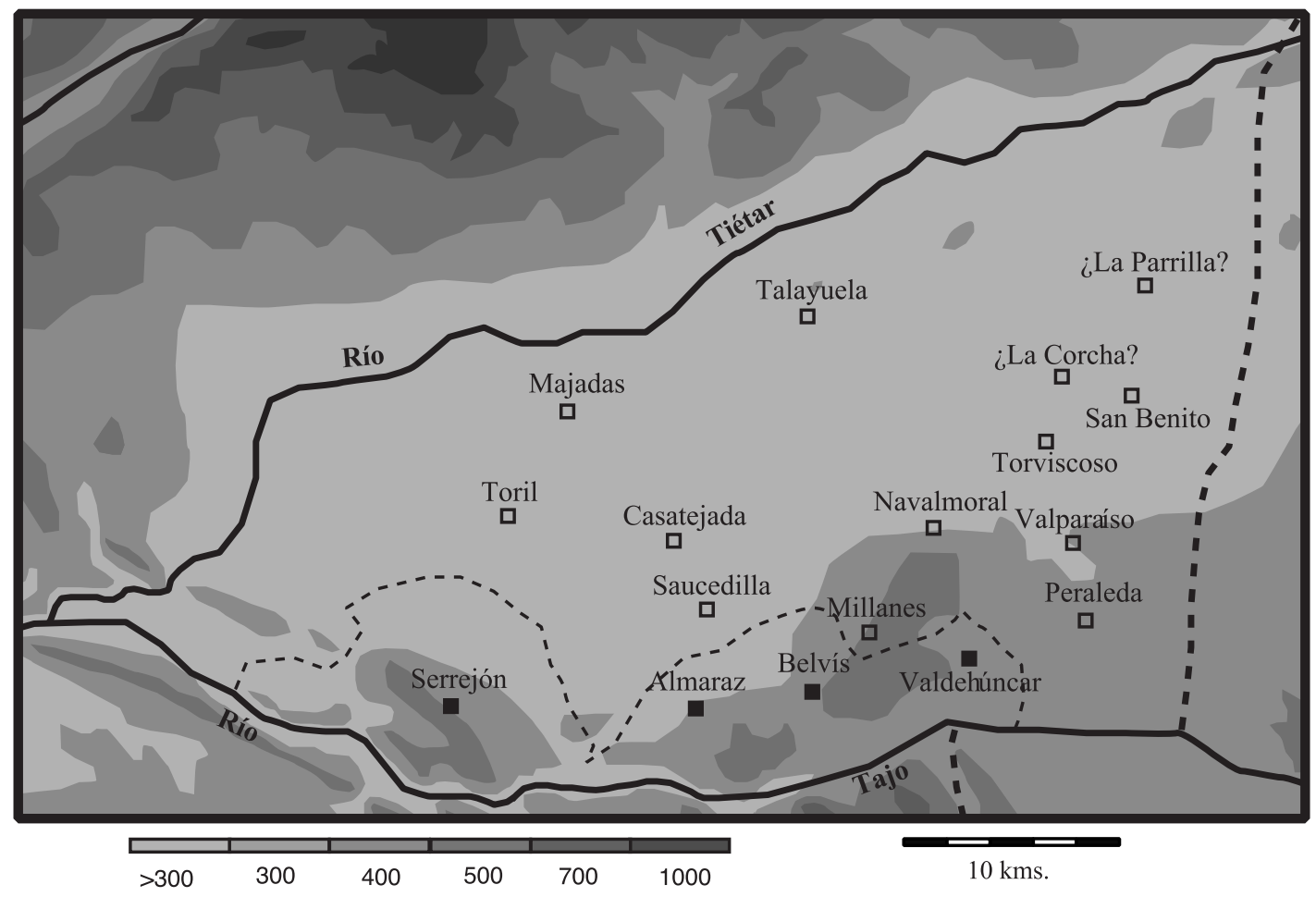

MAPA 1: El Campo Arañuelo a mediados del siglo XV

口 $\quad$ Aldea de Plasencia

- Villa o aldea de señorío

... Límite de la tierra de Plasencia

-. - Territorio señorializado 


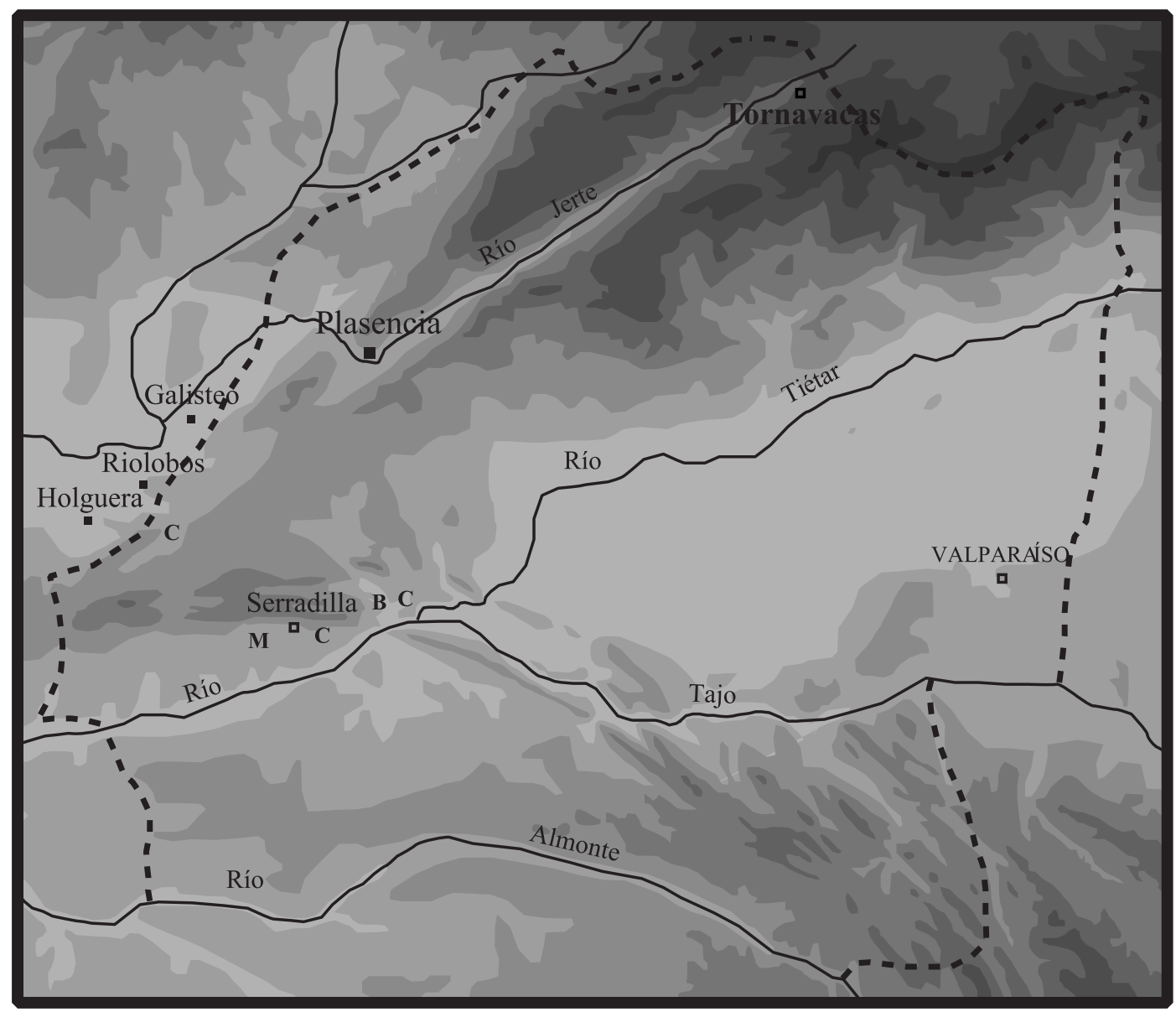

$20 \mathrm{kms}$.

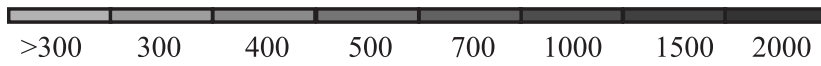

MAPA 2: El abastecimiento de pan en Tornavacas (c. 1450)

- Compra de cereal

M Mesiego (siega del cereal)

C Vecinos con cosecha propia
B Renta de bueyes

- Aldea-villa tierra de Plasencia

VALPAR. Doble vecindad 